Portland State University

PDXScholar

Winter 3-14-2014

\title{
Effects of Arbuscular Mycorrhizal Fungal Infection and Common Mycelial Network Formation on Invasive Plant Competition
}

Rachael Elizabeth Workman

Portland State University

Follow this and additional works at: https://pdxscholar.library.pdx.edu/open_access_etds

Part of the Fungi Commons, and the Plant Biology Commons

Let us know how access to this document benefits you.

\section{Recommended Citation}

Workman, Rachael Elizabeth, "Effects of Arbuscular Mycorrhizal Fungal Infection and Common Mycelial Network Formation on Invasive Plant Competition" (2014). Dissertations and Theses. Paper 2025.

https://doi.org/10.15760/etd.2024

This Thesis is brought to you for free and open access. It has been accepted for inclusion in Dissertations and Theses by an authorized administrator of PDXScholar. Please contact us if we can make this document more accessible: pdxscholar@pdx.edu. 
Effects of Arbuscular Mycorrhizal Fungal Infection and Common Mycelial Network Formation on Invasive Plant Competition

\author{
by \\ Rachael Elizabeth Workman
}

A thesis submitted in partial fulfillment of the requirements for the degree of

\author{
Master of Science \\ in \\ Biology
}

Thesis Committee:

Mitchell Cruzan, Chair

Sarah Eppley

Daniel Ballhorn

\title{
Portland State University \\ 2014
}




\begin{abstract}
Understanding the biotic factors influencing invasive plant performance is essential for managing invaded land and preventing further exotic establishment and spread. I studied how competition between both conspecifics and native co-habitants and arbuscular mycorrhizal fungal (AMF) impacted the success of the invasive bunchgrass Brachypodium sylvaticum in early growth stages. I examined whether invasive plants performed and competed differently when grown in soil containing AMF from adjacent invaded and noninvaded ranges in order to determine the contribution of AMF to both monoculture stability and spread of the invasive to noninvaded territory. I also directly manipulated common mycelial network $(\mathrm{CMN})$ formation by AMF to determine hyphal network contribution to competitive interactions.

I found that invasive plants performed most poorly (as indicated by decreased chlorophyll content, size and shoot dry mass) in invaded range soil against conspecifics. This could be two-pronged evidence for existing biotic pressure on the invasives to expand into adjacent noninvaded ranges. I also found a negative effect of AMF colonization and invasive plant performance, potentially indicating deleterious plant-soil feedbacks which could help maintain plant biodiversity at a community level. CMN effects were found to be interactive with root competition and directly affected the performance and nutrient status of B. sylvaticum. Although no direct correlations between AMF colonization levels and competition were found, CMN presence contributed significantly to plant growth and nutrient status. Therefore AMF, through infection and CMN formation, may be able to influence invasive plant growth and spread in the field.
\end{abstract}




\section{Dedication}

Dedicated to Mary Ann Workman, who taught me to always show up and never give up. And also to avoid kissing snapping turtles. 


\section{Acknowledgments}

Thank you to Mitch Cruzan for research assistance and for unwavering optimism, encouragement and support at every stage of my graduate student career. To my committee members Sarah Eppley and Daniel Ballhorn, who were instrumental in project guidance and editorial comments. To a myriad of graduate and undergraduate assistants, though none more so than Jacob Elias and Elinore Webb. To my labmates Gina Marchini, Tanya Cheeke and Caitlin Lee for technical and theoretical advice and commentary. To my other fellow graduate students who provided writing and research insight and clarity. To my intramural soccer team, The Goal-gi Complex, for providing an outlet for my aggression. To all of my wonderful friends and family who were my mirrors, extra table legs and sounding boards. This work was funded in part by a ForbesLea grant to Rachael Workman and by the Portland State University Department of Biology. 


\section{Table of Contents}

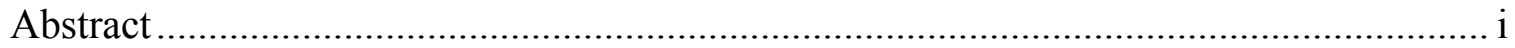

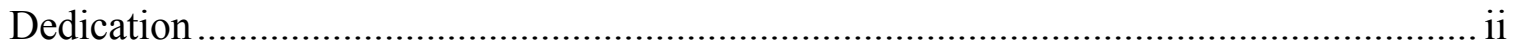

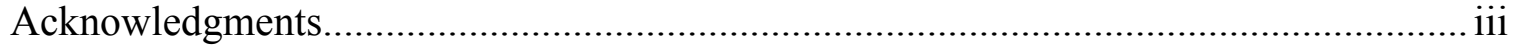

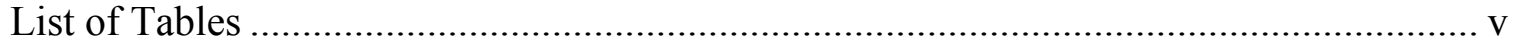

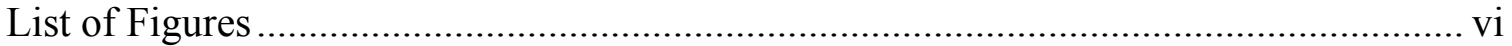

Chapter 1: Adjacent invaded and noninvaded range mycorrhizae differentially impact

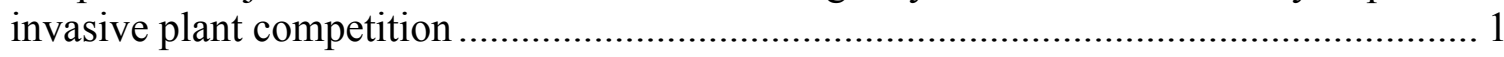

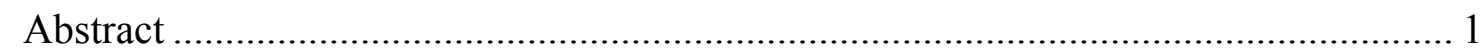

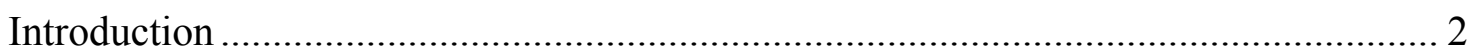

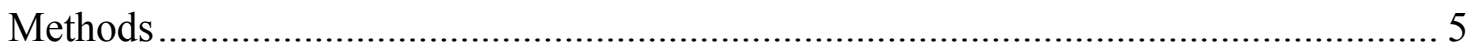

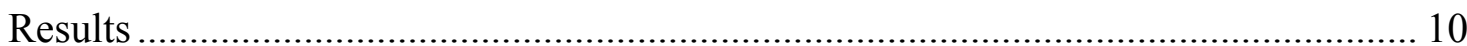

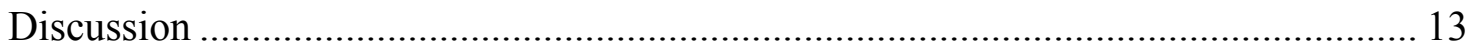

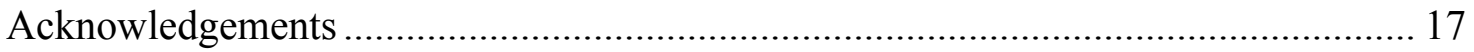

Chapter 2: Common mycelial networks impact belowground competition in an invasive

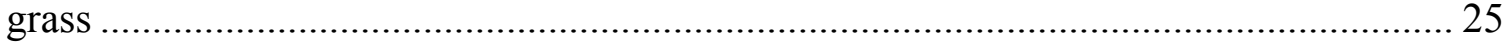

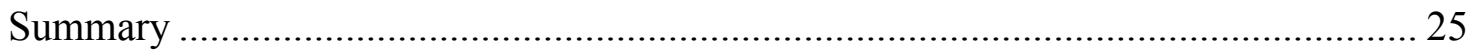

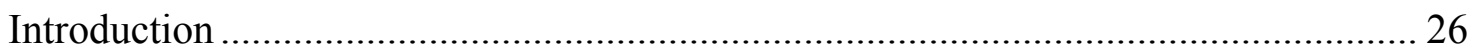

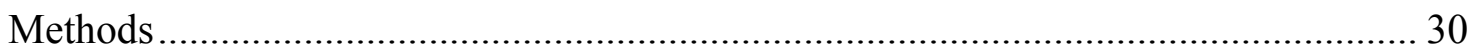

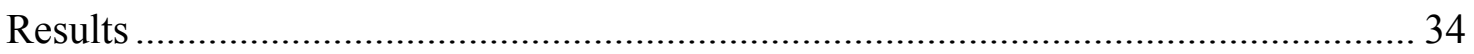

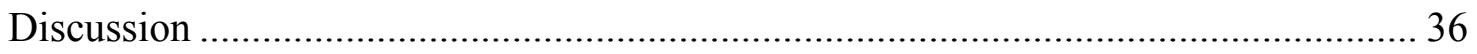

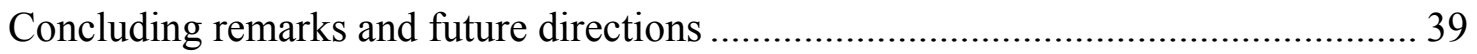

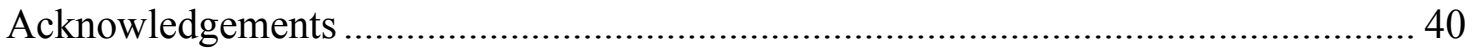

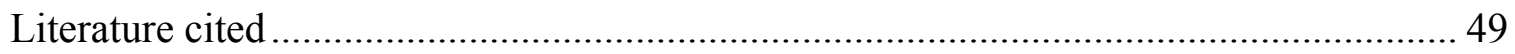




\section{List of Tables}

Table 1.1: ANCOVA model results showing plant growth and nutrient status responses to

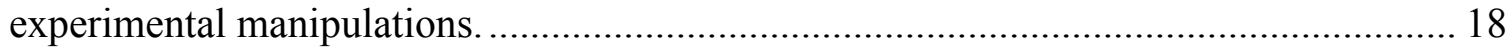

Table 2.1: Analysis of plant growth responses to experimental manipulations. ............. 42

Table 2.2: Analysis of invasive plant shoot nutrient status in response to experimental

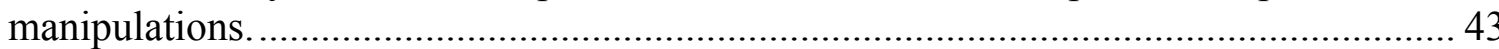




\section{List of Figures}

Figure 1.1: Area map of Corvallis, Oregon, showing three allopatric Brachypodium sylvaticum populations $\mathrm{C} 2, \mathrm{C} 3$, and $\mathrm{C} 5$.

Figure 1.2: Example images of adjacent invaded and noninvaded ranges within MacDonald-Dunn Forest in Corvallis, Oregon...

Figure 1.3: Sample block design illustrating all experimental treatment combinations... 20

Figure 1.4: Comparison of invasive and native plant performance in invaded and noninvaded range soils.

Figure 1.5: Mycorrhizal colonization differences between plant pairings grown in invaded and noninvaded range soils.

Figure 1.6: Competitive indices illustrating differences between plant pairings pooled and with and without AMF. 23

Figure 2.1: Sample block design containing all combinations of experimental treatments.

Figure 2.2: Effects of barrier type and AMF on invasive plant growth. 45

Figure 2.3: Effects of AMF, neighbor and barrier type on competitive index measures. 46

Figure 2.4: Interactive effects of mycorrhizal inoculation and barrier treatment on invasive plant growth and nutrient status.

Figure 2.5. Effects of barrier type on target invasive shoot nitrogen and phosphorus content. 


\title{
Chapter 1: Adjacent invaded and noninvaded range mycorrhizae differentially impact invasive plant competition
}

\begin{abstract}
1. Invasive-native plant competitive interactions can be mediated by symbioses with arbuscular mycorrhizal fungi (AMF), but the extent, directionality, and significance of this shift is context dependent. For example, plant-plant competitive intensity and AMF community composition can differ between adjacent invaded and noninvaded ranges, and this may affect the establishment and spread of invasive plants.

2. To test differential impacts of invaded and noninvaded range AMF communities on invasive plant competition, I grew invasive (Brachypodium sylvaticum) and native (Bromus carinatus) perennial bunchgrasses in pots inoculated with whole field soil collected from Oregon sites occupied by either an invasive monoculture (invaded range) or a mixture of native grasses (noninvaded range). Plants were grown in intra- and interspecific competitive pairings, in the greenhouse, for 100 days. Differences in plant growth parameters (size, shoot dry mass, and chlorophyll content) were used to determine how plant pairing and AMF presence and source impacted plant performance and competitive ability. AMF colonization percentages of all plants were assessed to determine the relationship between colonization extent and plant success.

3. Invasive plants performed best with noninvaded range AMF, as indicated by increased size, chlorophyll content, and shoot dry mass relative to those plants grown with invaded range AMF. Native grass performance was not significantly impacted by AMF source or by soil sterilization. Plants grown in intraspecific pairings fared worse than those in interspecific pairings, and size inequality between competitors was higher in sterile
\end{abstract}


controls than in live soil treatments. The presence, but not quantity, of mycorrhizal colonization was negatively associated with plant performance for both species and for both AMF communities.

4. Synthesis. Arbuscular mycorrhizal fungi from adjacent noninvaded and invaded ranges in Oregon forests decrease invasive plant growth relative to sterile controls, but increase invasive competitive success against natives, relative to other invasive conspecifics. Negative effects of invaded range AMF and conspecific competition on invasive plant performance suggests biotic pressures in invasive monocultures may promote invasive spread. Negative effects of noninvaded range AMF and facilitative effects of interspecific interactions may indicate stabilizing plant-soil feedbacks in the noninvaded range maintaining plant diversity.

\section{Keywords}

Competition; plant invasion; arbuscular mycorrhizal fungi (AMF); invaded and noninvaded ranges; plant-fungal (belowground) interactions

\section{Introduction}

Biotic interactions can shape plant community structure and determine whether plant populations will expand or contract over time (Hall et al. 1992, Chapin et al. 1998, Wisz et al. 2013). The identification of these biotic factors is crucial, as they could influence the success of invasive plant range expansion from established invasive monocultures into adjoining noninvaded spaces containing intact native plant communities (Theoharides and Dukes 2007, Davies and Svejcar 2008). Neighboring noninvaded and invaded ranges are often delineated by a number of biotic differences that define these plant communities (Levine et al. 2004). These differences may heavily 
influence both the extent and stability of the invaded range and the progression of these exotics into noninvaded territory. Examples of influential biotic differences include variation in competitor/ native plant diversity (Levine et al. 2004), presence and strength of enemies such as pathogens, parasites, and herbivores (Colautti et al. 2004, Torchin and Mitchell 2004), and interactions with soil community organisms, including arbuscular mycorrhizal fungi (Bever et al. 1997, Mitchell et al. 2006).

Arbuscular mycorrhizal fungi (AMF) are among the most common and ancient plant soil symbionts (Remy et al. 1994, Taylor et al. 1995). These fungi are obligate mutualists to their (primarily facultative) plant hosts. In exchange for a carbon cost ranging from $4-24 \%$ of fixed photosynthates, AMF are capable of enhancing nutrient uptake for their host plant (Smith and Read 2008). Additionally, AMF can provide a suite of benefits ranging from pathogen protection (Sikes 2010, Wehner et al. 2010, Cameron et al. 2013), to the alleviation of drought (Auge 2001), salt (Evelin et al. 2009) and heavy metal stress (Hildebrandt et al. 2007), to boosting reproductive capabilities (Koide 2000). Although generally considered mutualists, plant-AMF interaction effects are context dependent (Hoeksema et al. 2010), and operate on a positive-neutral-negative continuum (Johnson et al. 1997).

Plant-AMF associations can shape plant community ecology (Grime et al. 1987, Hartnett et al. 1993, Bever et al. 2001, Reynolds et al. 2003, Scheublin et al. 2007). The mycorrhizal symbiosis is capable of altering competitive interactions between plants (Moora and Zobel 1996, Casper and Castelli 2007, Wagg et al. 2011), including invasive plants, both with conspecifics and native competitors (Goodwin 1992, Marler et al. 1999, Callaway et al. 2001, Bray et al. 2003). Potential mechanisms for competitive alteration 
include plant-soil feedbacks (Bever et al. 1997) and either resource sharing or competition through common mycelial networks that connect multiple plants (Hart et al. 2003, Selosse et al. 2006). Additionally, AMF community composition can differentially affect plants (van der Heijden et al. 2003), and it is known that AMF communities can vary between the roots of native plants grown in close proximity with invasives and with conspecifics (Hawkes et al. 2006, Mummey and Rillig 2006). If AMF community composition functionally differs between adjacent invaded and noninvaded ranges, then it could be expected that this differential functionality would affect plant community ecology. Ecological impacts could include influence of invasive range stability and persistence, as well as progression of invasives into proximal noninvaded spaces containing intact native plant communities. However, experiments testing the effects of invaded and noninvaded range AMF communities on invasion success are lacking. In this study I use the newly invasive, perennial bunchgrass Brachypodium sylvaticum (Hudson) Beauv (slender false brome) to test the impacts of invaded and noninvaded range AMF inocula on plant performance and competition. B. sylvaticum is native to Eurasia and North Africa, where it is tolerant to a broad spectrum of elevation, light environments, and precipitation regimes (Rosenthal et al. 2008). It is listed as a quarantined invasive species in California, Washington, and Oregon, USA (CDFA 2013; NWCB 2013; ODA 2013), and has been sighted in low abundance at several locations in eastern North America as well (Roy et al. 2011). B. sylvaticum has been spreading rapidly since the 1980s (Rosenthal et al. 2008), and unless contained, is likely to continue its spread across North America (Roy et al. 2011). The invasive success of B. sylvaticum has been attributed to several factors, including disturbance, soil compaction by human 
activity, and high seed load (Taylor, in review). B. sylvaticum is ideal for use in this study, as previous studies have found evidence of mycorrhizal influence in greenhouse experiments and indications of mycorrhizal effects in the field across multiple sites in Oregon (Lee, unpublished data).

I investigated the impacts of invaded and noninvaded range arbuscular mycorrhizal fungal communities on performance and competitive success of $B$. sylvaticum and its native competitor from Oregon plant communities, Bromus carinatus. If invaded and noninvaded range AMF differentially impact invasive plant growth and competition, these biotic factors could determine whether invasive plants will remain in their stable monocultures or move into noninvaded native plant communities in the field. This experiment addressed two questions: 1) Do AMF from the invaded range contribute to invasive monoculture stability by positively impacting exotic plant performance and competition relative to natives? and 2) Do AMF in the noninvaded range improve biotic resistance to invasive spread by positively associating with natives relative to invasive plants? I found that AMF from both the invaded and noninvaded ranges decreased invasive and native plant performance, suggesting a negative feedback that may act to promote plant biodiversity in the noninvaded range and inhibit overcrowding in the invasive monoculture.

\section{Methods}

Seed and soil collection

Seeds of Brachypodium sylvaticum (slender false brome) and its native competitor Bromus carinatus (California brome) were collected from three allopatric sites in Corvallis, Oregon, USA (C2, C3, C5 - C2: 44.63124 -123.30456; C3: 44.71016 - 
123.31621; C5: 44.64313 -123.33648) separated by a distance ranging from three to nine kilometers (Figure 1.1). Bromus carinatus was chosen as it commonly co-occurs with $B$. sylvaticum in forest edges and under partial shade conditions. Like B. sylvaticum, B. carinatus is a C3 grass, cespitose, facultatively mycotrophic, diploid, and perennial. As mycorrhizae differentially impact plants with differing life history, phenological, and physiological traits (Hetrick et al. 1990, Newsham et al. 1995), it was crucial to choose a competitor with these similar characteristics.

Corvallis, Oregon has been identified as one of two original introduction sites (Ramakrishnan et al. 2010), and false brome invasion is noxious in this region, especially in the dense coniferous understory found throughout MacDonald-Dunn forest. Three invaded sites were chosen within this forest based on the present of a dense B. sylvaticum monoculture. Three adjacent noninvaded sites were characterized by the presence of Bromus carinatus cohabitating with other native grasses and absent of B. sylvaticum (Figure 1.2). Seeds were collected from all sites, and seed maternal families were kept distinct.

Whole rhizospheric field soil was collected from ten native and invasive grasses at each of the six ranges to serve as mycorrhizal inoculum for the greenhouse experiment. We then made the assumption that the AMF community found in the rhizosphere of $B$. carinatus was characteristic of the AMF found throughout the adjoining noninvaded range, while the AMF community present in the rhizosphere of B. sylvaticum was characteristic of the AMF found throughout the invaded range. Although potential AMF differentiation within sites could confound this assumption, multiple soil samples were collected to correct for this, which sampled a range of plants in age and habitat 
characteristics, and data were interpreted with caution. Ten one gallon soil samples were taken from three sites in Corvallis, for each of the two ranges within site (invaded and noninvaded; 30 samples each; 60 total). To ensure homogeneity in edaphic properties such as soil nutrient content and texture between the three sites, all soil from each range was mixed prior to use, creating to soil inocula ( $\mathrm{LI}=$ live invaded, $\mathrm{LN}=$ live noninvaded).

\section{Experimental design}

A full factorial experimental design manipulating AMF presence (live or sterile),

AMF source (invaded or noninvaded range), and plant pairing (where $\mathrm{NN}=$ native-native, $\mathrm{IN}=$ invasive-native, $\mathrm{NI}=$ native-invasive, $\mathrm{II}=$ invasive invasive) was implemented under greenhouse conditions for 100 days. All plant pairings were transplanted as seedlings into $45 \%$ sterile sand, $45 \%$ potting soil (Sunshine Mix \#3, Sun-Gro Horticulture), and $10 \%$ whole field soil inoculum (AMF source) in $1.8 \mathrm{~L}$ treepots $(10 \mathrm{~cm}$ x $24 \mathrm{~cm}$; model TP49, Steuwe and Sons, Albany, OR).

To increase seedling germination, seeds were stratified at $4^{\circ} \mathrm{C}$ for 30 days. After this period, seeds were sown into a tray of potting soil and germinated seedlings were transplanted into competitive pairings after 15 days. This transplant step was used, rather than direct planting, due to low germination rates of both species and to attempt to equalize survival probabilities.

To delineate effects of soil biota on plant growth, plants were grown in soil containing either $10 \%$ live or sterilized (doubly autoclaved, $60 \mathrm{~min}$ at $121 \mathrm{deg}, 24$ hours between two cycles) whole field soil inoculum. To minimize effects of differing edaphic properties on plant pairings, as well as the effects of the characteristic nutrient flush which accompanies soil sterilization (Troelstra et al. 2001, Cui and He 2009), only 10\% 
field soil inoculum was used, and sterile controls were set up for each soil type, totaling four soil treatments (SN, SI, LI, LN; where SN = sterile noninvaded, SI = sterile invaded, $\mathrm{LI}=$ live invaded, and $\mathrm{LN}=$ lived noninvaded).

Treatments were arranged into randomized blocks in a greenhouse. For intraspecific pairings (II and NN), two different maternal families were used to exclude competition from identical genotypes. Nine maternal families were used for each plant species, and maternal family pairings were randomly assigned and placed in an incomplete block design comprising eighteen blocks of twelve, comprising 16 treatment combinations (Figure 1.3). Pairs of pressure plants were placed in a single row surrounding the experimental blocks to eliminate edge effects and standardize aboveground competitive intensity.

Plants were grown for 100 days, with height and tiller number measures taken every 25 days and chlorophyll content measures taken on day 100 with a SPAD-502 chlorophyll meter, and were later standardized to depict amount of chlorophyll per area and dry weight using a chlorophyll standard curve for both plant species. Upon destructive harvest, roots and shoots were separated and shoots were dried for 48 hours and weighed to obtain shoot dry mass. Roots of most competitive pairings were severely entangled and thus root dry mass and total plant biomass measures were not obtained. A portion of untangled root was removed from each plant, stained (Koske and Gemma 1989) and the percentage of mycorrhizal colonization was determined using the slideintersect method (McGonigle et al. 1990). Microscope slides of plant roots were doubleblinded, and were assigned a number in the order in which they were made. That number 
was the only labeling on the slide- in this manner, unintentional bias in slide reading was avoided.

\section{Infection potential assay}

To investigate AMF viability and propensity for colonization in the collected soils, an independent assay was run, assessing mean mycorrhizal infection potential on a generalist host, Sorghum bicolor. Prior to mixing soils from the six sites, $300 \mathrm{~mL}$ of each of the 30 samples was removed and used as inoculum in a one gallon pots with 45:45:10 sand: potting mix: inoculum mixture. Fifteen sorghum seeds were sown per pot and thinned to one seedling per pot at fourteen days. At 60 days, sorghum were harvested, and their roots were washed, cleared, stained, subsampled, mounted on glass slides, and read to assess for mycorrhizal colonization percentage (McGonigle et al. 1990).

\section{Statistical analysis}

For each pot a neighbor and target plant was identified. For intraspecific pairings this was determined by coin flip; for interspecific pairings target designation was divided evenly and randomly (by random number generation) between invasive and native plants. The effect of competition was indicated by the effect of neighboring plant properties (size, shoot dry mass) on target plant properties. The "winner" of a competitive interaction was designated as the individual least negatively impacted by the growth of the other. Plant performance was quantified as a measure of relative size (height*tiller), shoot dry mass, and nutrient status (chlorophyll content) of the plants at the end of the growth period.

Competitive indices were determined by calculating the ratio of target plant size in a given pairing to the fixed mean of target in both intra- and interspecific pairings, and then subtracting by 1 to center the mean at zero. In this manner, average plant 
performance in a given treatment could be directly compared to the average for all treatments, provided a relative scale by which to assess neighbor and mycorrhizal impacts.

To examine the effects of AMF source and neighbor plant growth on target plant performance, an analysis of covariance (ANCOVA) model was constructed using soil type (invaded or noninvaded) and AMF presence/absence as fixed effects, as well as the interaction between the two. Neighbor size at harvest (a measure of competitive intensity) was included as a covariate. Target size at harvest, shoot dry mass and chlorophyll content were used as indicators of plant performance. Tukey's HSD was used to determine significant differences between groups.

To assess different impacts of noninvaded and invaded range AMF communities on target plant growth, an additional ANCOVA, sorted by presence/absence of AMF infection, was run with target chlorophyll content, SDM and size at harvest as response variables. Soil type (invaded or noninvaded) was included as a fixed effect, and neighbor size at harvest was used as a covariate.

Statistical analyses were run in SAS (SAS Institute Inc, Cary, NC, USA) and R 3.0.1 (R Core Team, 2013).

\section{Results}

ANCOVA results: Target plant growth influenced by AMF, soil type and neighbor size

Results of the ANCOVA model revealed that shoot dry mass (SDM, g) and chlorophyll content (mg chl/g plant dry weight) were significantly lower with AMF infection than without, and that SDM and size at harvest (height* tiller number) were significantly higher in noninvaded range soil than invaded range soil. Neighbor size at 
harvest (a measure of competitive intensity) only affected target size in terms of increasing target chlorophyll content. There was also a significant interaction of soil type (invaded and noninvaded) and AMF infection, but only for target size at harvest (Table

\section{1).}

Invaded and noninvaded range soils differentially impact target plant performance

Plants grown in noninvaded soil were $13 \%$ larger in size and $24 \%$ heavier in shoot dry mass measures, and had 7\% more chlorophyll than those grown in invaded range soil (significant at $\mathrm{p}=0.05,0.01$, and 0.02 for each effect, Figure 1.4). When invasive and native target plants were considered separately, only invasive targets responded significantly to soil treatment, as evidenced by a $9 \%$ decrease in mean chlorophyll content, $18 \%$ decrease in shoot dry mass and $15 \%$ decrease in size in invaded range soil (significant at $p=0.11,0.016$, and 0.006 ), whereas no significant differences in these response variables were found for the natives. There were no significant differences in size, SDM or chlorophyll content between plants grown in the two sterile soil treatments.

When only plants grown with AMF were examined, it was found that plants grown in noninvaded range soil had $15 \%$ more chlorophyll than those grown in invaded range soil $\left(\mathrm{F}_{1,68}=10.01, \mathrm{p}=0.003\right)$. This effect was not observed for size $\left(\mathrm{F}_{1,71}=0.72\right.$, $\mathrm{p}=0.400)$, or shoot dry mass $\left(\mathrm{F}_{1,70}=1.84, \mathrm{p}=0.181\right)$, although means for both variables were higher for plants grown in noninvaded range soil.

\section{Soil sterilization (removal of AMF community) impacted plant performance}

Most plants grown in live soil treatments were colonized by arbuscular mycorrhizal fungi; however, some uncolonized plants were found in all treatment combinations. Likewise, occasionally low levels of colonization (ranging from 1-9\%) 
were found in some sterile treatments, potentially due to spore splash-over from watering. These plants were removed from the analysis, as to avoid confounding relationships between soil sterilization effects and absence of mycorrhizal colonization effects.

Native plants exhibited differential colonization levels between noninvaded and invaded live soil treatments, whereas invasive colonization levels did not change (Figure 1.5). No significant correlations were found between the quantity of AMF infection and plant performance. This effect was consistent regardless of target or neighbor plant identity.

\section{Target and neighbor identity influence target performance}

Invasive plants responded poorly to growth with conspecifics, as indicated by a $17 \%$ decrease in size, $22 \%$ decrease in shoot dry mass (SDM), and 5\% decrease in chlorophyll content relative to growth with natives (significant at $\mathrm{p}=0.007,0.05$ and 0.05 for each effect, respectively). Native plants performed significantly better when grown in interspecific pairings as well, as indicated by a $16 \%$ increase in size, $37 \%$ in shoot dry mass, and $12 \%$ in chlorophyll content (significant at $p=0.23,0.09$ and 0.02 for each effect, respectively).

Competitive indices (the ratio of target plant size to the fixed mean of all target plants size) revealed a $250 \%$ increase in interspecific over intraspecific interactive intensity for invasives and $270 \%$ for natives (significant at $\mathrm{p}=0.14$ for invasive target plants and $p=0.06$ for native target plants; see Figure 1.6). Competitive ability was not found to be different between plants grown with live invaded and noninvaded range AMF communities, meaning there was no interaction between AMF source and effect of neighbor size on target performance. 
Infection potential differs between invaded and noninvaded range soil

All sorghum plants grown in noninvaded range soil were infected by AMF, with a mean root length colonization of $15 \%$. None of the plants grown in invaded range soil showed any signs of infection, including vesicles, arbuscules, or aseptate rope-like hyphae characteristic of AMF.

\section{Discussion}

Negative biotic pressures in the invaded range, such as plant-plant competition and antagonistic soil biota, may favor invasive plant range expansion into adjacent noninvaded native plant communities. In my experiment, invasive plant growth was stunted when invasives were grown with conspecifics, and when grown with invaded range AMF. The deleterious impact of invaded range soil fungal communities on invasive plants is consistent with many previous studies (Nijjer et al. 2007, Suding et al. 2013) and supports claims that soil conditioned by invasives is often detrimental to both invasive and native plants. Interestingly, noninvaded range AMF did not benefit invasive or native plant growth either, relative to sterile soil controls. However, negative effects of AMF on individual plants may equate to positive community effects, and AMF in both ranges will have consequences for the maintenance of native communities and invasion dynamics.

Mycorrhizal infection was slightly negatively correlated with shoot dry mass and size in both native and invasive species, but this difference was not considered conclusive. However, there was a clear negative effect of the presence of AMF. Although AMF are typically considered mutualists, it is not uncommon to see an inverse relationship between mycorrhizal infection and plant host performance, especially if the host is a 
grass species (Newsham et al. 1995). Grasses, with their fibrous root systems, have a much higher root surface area for nutrient acquisition, and thus are more likely to be less dependent upon the mycorrhizal mutualism for nutritional support. Therefore, it is possible that grasses colonized by AMF may be allocating carbon to roots to support the mutualism, while not receiving the benefit of increased nutrient availability characteristic of the AMF symbiosis, so the AMF are acting as a carbon drain. Another potential mechanism for the inverse relationship between AMF infection and plant performance is resource competition between host plants and their symbiotic fungi for nitrogen, which could cause a decrease in biomass in infected plants (Facelli et al. 2009, Hodge et al. 2010). Nitrogen competition is a likely explanation, as nitrogen limitation was induced by limited soil space in my pots and no fertilizer addition. Although mycorrhizal infection reduced plant growth in the greenhouse, this does not mean these mycorrhizae would not act mutualistically in the field. There are many beneficial effects of AMF that could be important in the field, such as increased pathogen protection, salt and heavy metal tolerance, and drought resistance, which I would have been unable to see in this controlled experiment because those stressors were not present (Smith et al. 2010). A repetition of this experiment in the field would elucidate whether AMF would adversely affect plant growth under natural conditions.

No difference in percent AMF colonization was observed between invasive plants grown in invaded and noninvaded range soil, but native plants were significantly less colonized in invaded range soil than noninvaded range. Interestingly, the infection potential assay also revealed no colonization in sorghum plants grown in invaded range soil, but an average $20 \%$ colonization in the noninvaded range soil. The decrease in 
colonization of native grass Bromus carinatus, and sorghum, grown in live invaded range soil may suggest invasive plant-mycorrhizal specificity within the invaded range. The lower mycorrhizal colonization of native plants in invaded range soil also lends support to the hypothesis that native AMF communities are suppressed by invaders (Hawkes et al. 2006, Mummey and Rillig 2006). Invaded range AMF is clearly capable of infecting plants, but only invasive plants in my experiment. However, considering the overall effects of AMF are neutral to negative, this may not have significant consequences for invasion success.

Removal of the mycorrhizal community by sterilization increased the growth of Brachypodium sylvaticum, whereas no growth differences were found with the native grass. Enhanced performance of invasives in soil devoid of biota may facilitate invasion in disturbed sites, where AMF abundance is likely lower than in undisturbed soils (Jasper et al. 1991). Interestingly, field studies have shown B. sylvaticum to have lower spore abundance and root AMF colonization than native competitor Elymus glaucus, within identical habitats and consistently between multiple sites in Oregon (Caitlin E. Lee, unpublished data). The lower spore abundance in invaded range soils, coupled with my findings that $B$. sylvaticum thrives in sterile soil, suggests that false brome may be less dependent upon the mycorrhizal mutualism than native plants, at least the two (E. glaucus and B. carinatus) tested.

Brachypodium sylvaticum performed most poorly when grown with conspecifics. This was not expected, as B. sylvaticum is capable of forming dense and stable monocultures in natural settings. However, due to soil volume limitations and no fertilizer addition, nutrient limitation induced in my experiment was likely more intense 
than that found in Pacific Northwest coniferous forests (Chen et al. 2002), where many of these dense invasive monocultures are found. A previous B. sylvaticum competition experiment found that false brome competed superiorly with conspecifics (Gina L. Marchini, unpublished data) under nitrogen conditions analogous to field expectations. Therefore, resource limitation may increase intraspecific competitive intensity, and invasive monoculture stability may be a product of adequate nutrient availability. Marchini also used large bins in which soil space was not limiting; therefore, pot effects and spatial limitations could have contributed to the competitive effects seen in this experiment. The degree of competition introduced in pots with a limited soil space is likely higher than that in the field, even in dense monocultures.

As was the case with invasives, native target plant growth was also enhanced in interspecific competition, relative to growth with native conspecifics. Native intraspecific competitive intensity may be due to a high (and overlapping) resource requirement of native conspecifics, and may explain why this native does not reach high densities in the field sites I observed. The large increase in native plant growth in interspecific pairings, but only with AMF present, supports microbial-mediated niche partitioning between the invasive and native grass species (Reynolds et al. 2003).

My study supports the importance of arbuscular mycorrhizal fungi in the mediation of invasive-native competitive interactions. The alteration of inter- and intraspecific competitive intensity with the addition of AMF implies greater competitive inequality between competing species with AMF present. Thus, AMF may help shape current plant community structure and future spread. Although differential effects of invaded and noninvaded range AMF on competition were not found, they did affect 
individual plant growth, which could translate to competitive effects on different spatial scales.

\section{Acknowledgements}

Thank you to Cruzan lab members T. Cheeke, C. Lee, C. Maraist, N. Jimenez and C. Hernandez for help with the harvest and sample processing. To S. Eppley for editorial comments and M. Chmielewski for assistance with data analysis. This work was funded by Portland State University Department of Biology. 
Table 1.1: ANCOVA model results showing plant growth and nutrient status responses to experimental manipulations.

AMF (+/-), soil type (invaded or noninvaded), their interaction were included as fixed effects, and neighbor size at day 100 (NS100), a measure of competitive intensity, was used as a covariate. Shoot dry mass of target plants was found to be significantly affected by AMF and soil type, chlorophyll content was influenced by soil type and an interaction between soil and AMF, and size (height*tiller number) was explained by AMF presence and neighbor size at harvest. F values given numerically, significance denoted (NS = not significant, $\left.{ }^{*} \mathrm{p}<0.05,{ }^{* *} \mathrm{p}<0.01\right)$.

\begin{tabular}{lcccc}
\hline $\begin{array}{l}\text { Treatment } \\
\text { effect }\end{array}$ & df & $\begin{array}{c}\text { Shoot dry } \\
\text { mass }(\mathbf{g})\end{array}$ & $\begin{array}{c}\text { Chlorophyll } \\
(\mathbf{m g} \mathbf{C h l} / \mathbf{g})\end{array}$ & $\begin{array}{c}\text { Size at harvest } \\
(\mathbf{c m})\end{array}$ \\
\hline AMF & 1 & $\mathbf{6 . 7 9 * *}$ & 1.39 & $\mathbf{4 . 4 4 *}$ \\
Soil type & 1 & $\mathbf{5 . 7 3 *}$ & $\mathbf{4 . 4 4 *}$ & 3.11 \\
Soil*AMF & 1 & 0.01 & $\mathbf{4 . 2 3 *}$ & 0.07 \\
NS100 & 1 & 2.69 & 0.52 & $\mathbf{9 . 3 5 * *}$ \\
\hline \hline
\end{tabular}


Figure 1.1: Area map of Corvallis, Oregon, showing three allopatric Brachypodium sylvaticum populations $\mathrm{C} 2, \mathrm{C} 3$, and $\mathrm{C} 5$. Locations were separated by distances ranging from 3 to 9 kilometers. Adjacent invaded and noninvaded ranges were identified at each of the three sites, totaling six sampling locations.

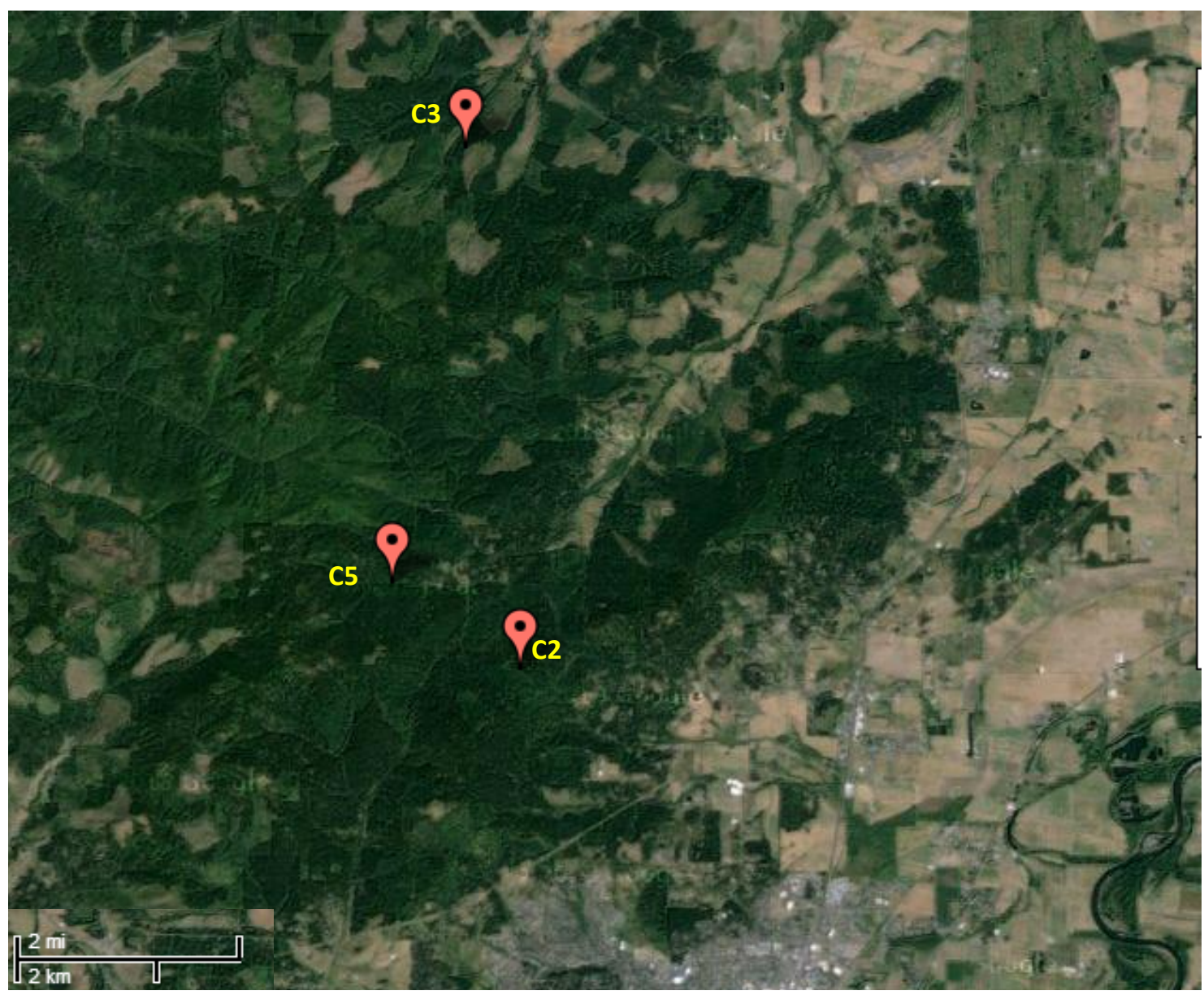


Figure 1.2: Example images of adjacent invaded and noninvaded ranges within MacDonald-Dunn Forest in Corvallis, Oregon.

Top- A monoculture of Brachypodium sylvaticum in a mixed stand (coniferous/deciduous) forest. Bottom- an adjacent noninvaded range.
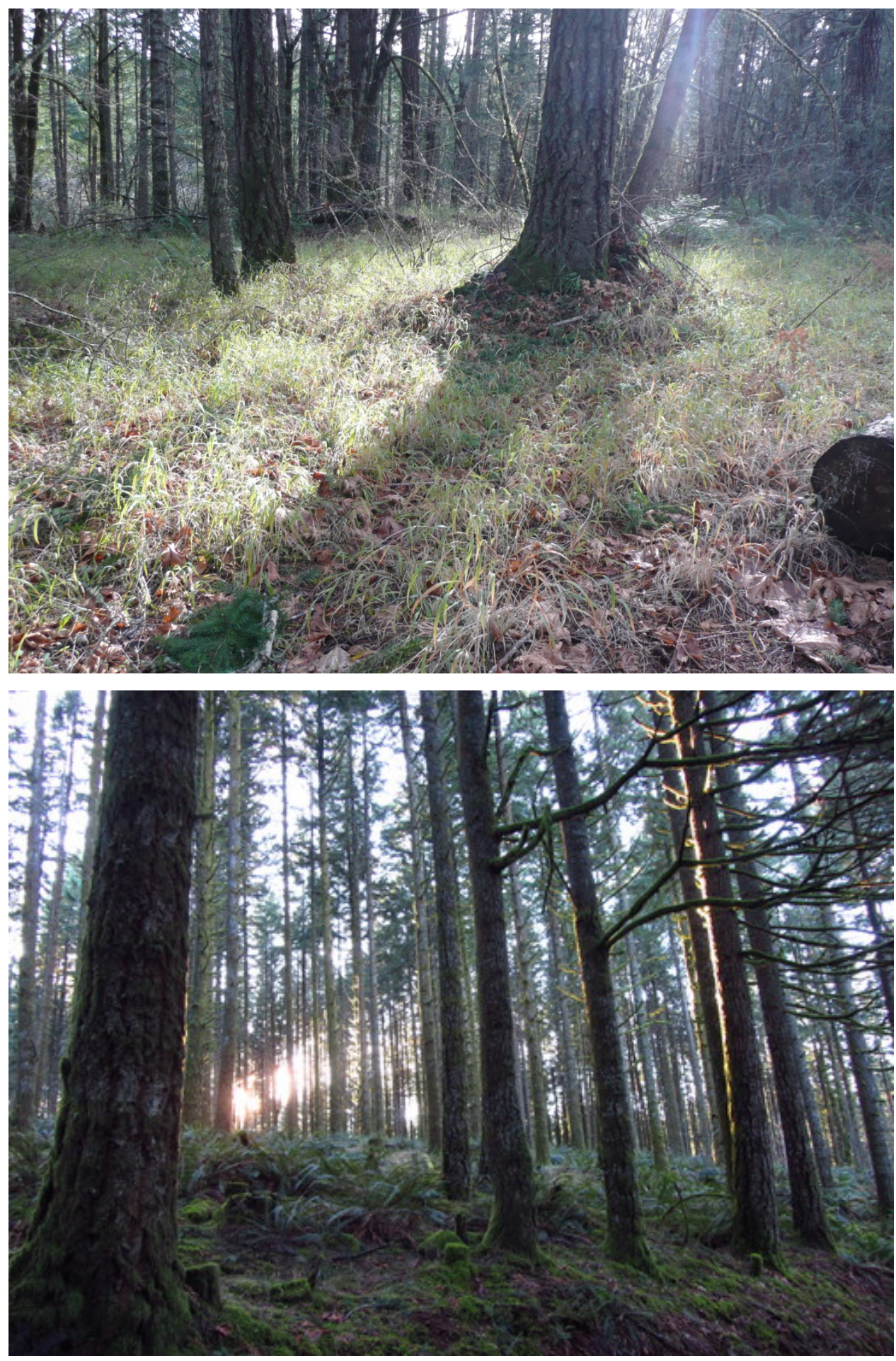
Figure 1.3: Sample block design illustrating all experimental treatment combinations. Soil treatment given by color and designated below block, and plant pairing given by lettering and designated to the right of block.

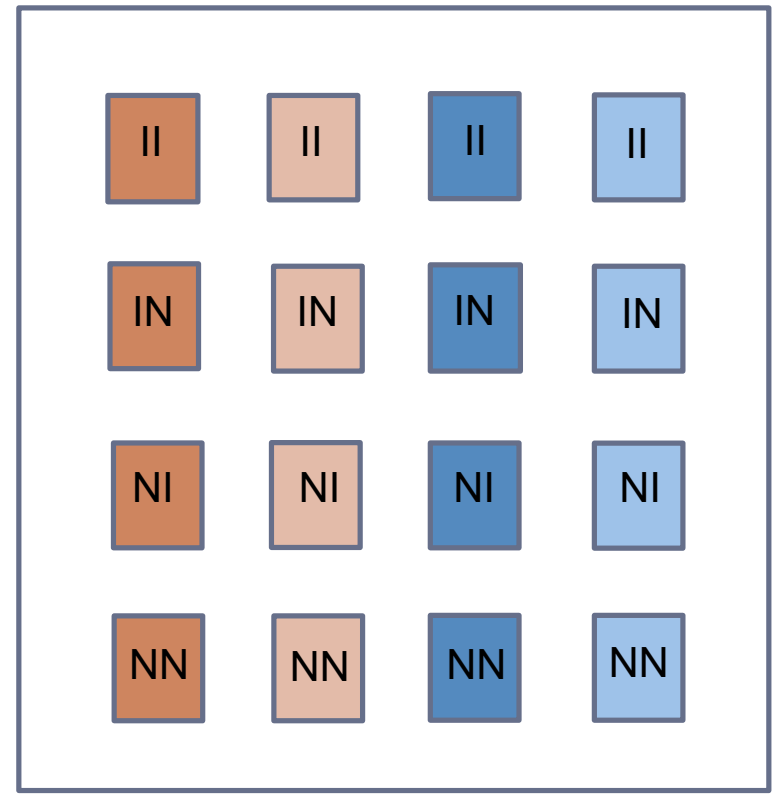

II: Invasive-invasive, Brachypodium sylvaticum in intraspecific competition.

IN: Invasive-native, invasive target plant and native neighbor

NI: Native-invasive, native target plant and invasive neighbor

NN: Native-native, Bromus carinatus in intraspecific competition.

Sterile (autoclaved) soil from an invaded range (SI)

Sterile (autoclaved) soil from a noninvaded range (SN)

Live soil from an invaded range (LI)

Live soil from a noninvaded range (LN) 
Figure 1.4: Comparison of invasive and native plant performance in invaded and noninvaded range soils.

Invaded and noninvaded range soils differentially impacted plant pairings (II = invasiveinvasive, $\mathrm{IN}$ = invasive-native, $\mathrm{NI}$ = native-invasive, $\mathrm{NN}$ = native-native; with the first letter indicating target plant and the second indicating neighbor) for both size (height in $\mathrm{cm} *$ tiller number), shoot dry mass, and chlorophyll content. Means given, error bars represent standard error. Asterisks denote significant differences within each plant pairing between soil treatments.
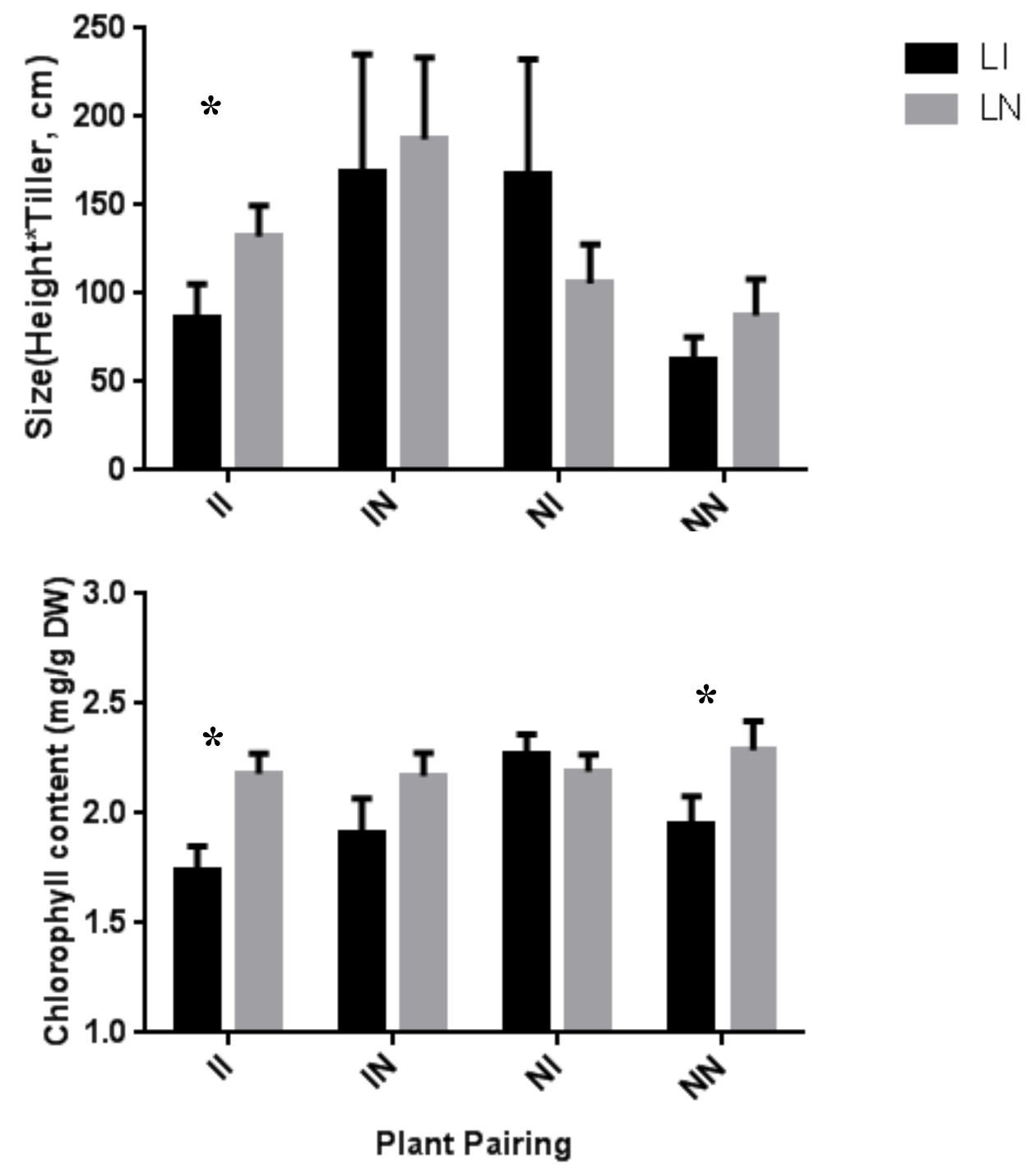
Figure 1.5: Mycorrhizal colonization differences between plant pairings grown in invaded and noninvaded range soils.

Plant pairing ( $\mathrm{II}=$ invasive-invasive, $\mathrm{IN}$ = invasive-native, $\mathrm{NI}=$ native-invasive, $\mathrm{NN}=$ native-native; with the first letter indicating target plant and the second indicating neighbor) was only significantly affected by soil type in native intraspecific competition. Additive colonization (AMF target + AMF neighbor) was used to highlight the effects of soil treatment on the total community (target + neighbor $+\mathrm{AMF}$ ). Means given, error bars represent standard error. Asterisks denote significant differences within each plant pairing between soil treatments.

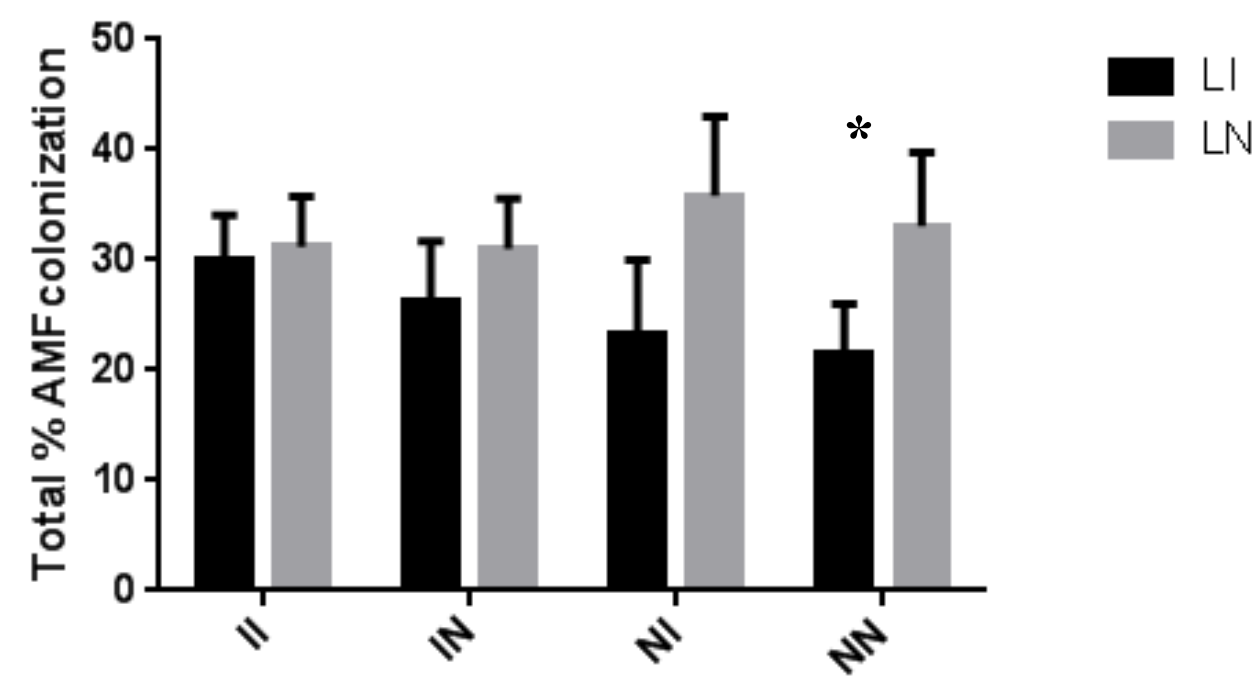

Plant Pairing 
Figure 1.6: Competitive indices illustrating differences between plant pairings pooled and with and without AMF.

Competitive indices, the ratio of target plant size in given pairings to the mean of all target plant sizes for invasives and natives, revealed higher intraspecific competitive intensity for both plant species (top). When plant pairings were split into AM and nonAM plants, there was no significant difference found between plant pairings grown without AMF (bottom graph, black bars), but an increase in invasive plant performance when grown with native competitors with AMF (bottom, gray bars). Error bars represent standard error. Asterisks denote significant differences within each target plant between neighbor plant species.
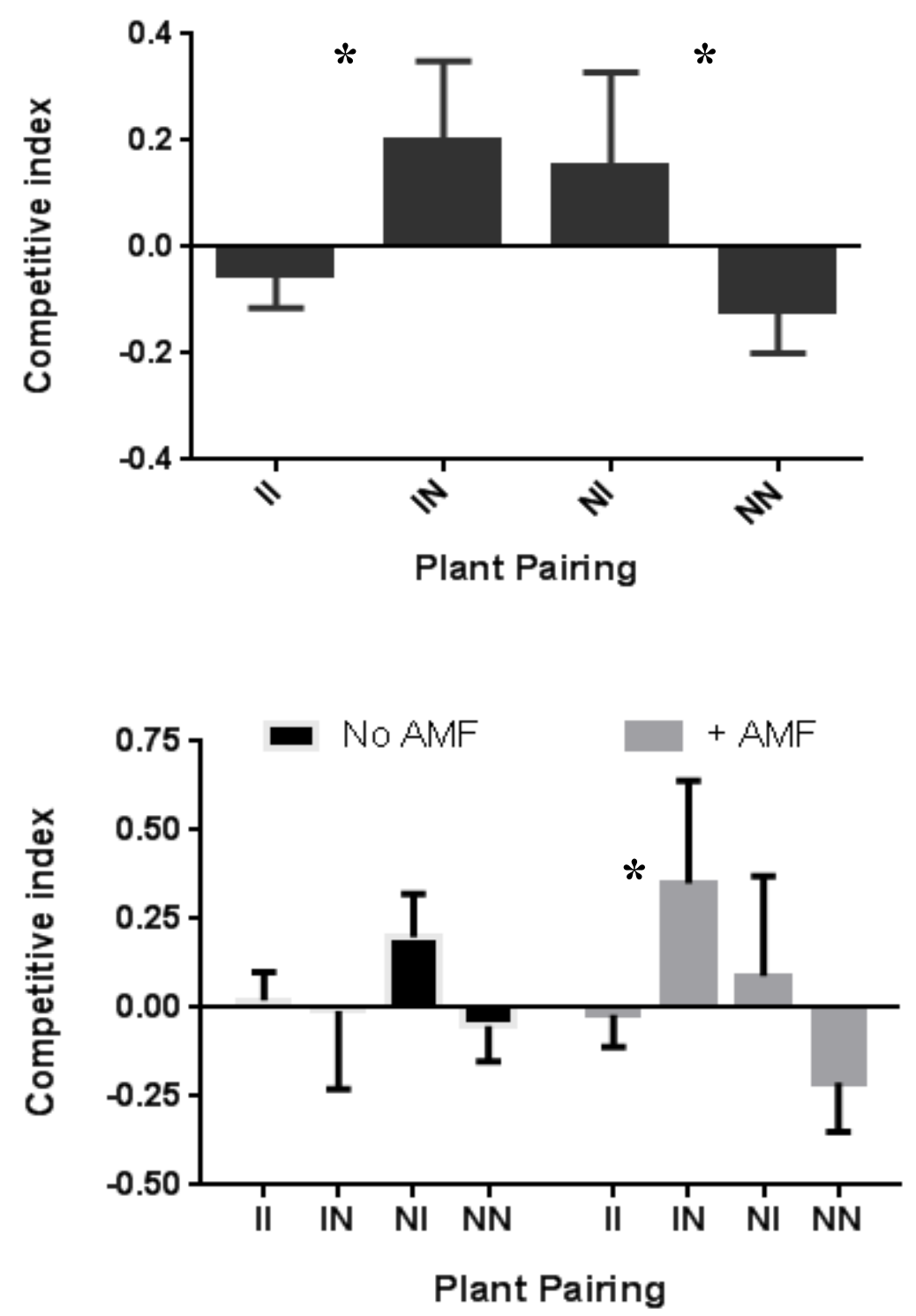


\section{Chapter 2: Common mycelial networks impact belowground competition in an invasive grass}

\section{Summary}

Mycorrhizal hyphal complexes connecting proximate host plants, termed common mycelial networks (CMNs), could affect competitive outcomes and community composition, but few experiments have been conducted to test this hypothesis. I grew the invasive grass Brachypodium sylvaticum in intra- and interspecific (with native grass Bromus vulgaris) pairings in a greenhouse for 60 days and controlled for the effects of $\mathrm{CMN}$ and root interactions by manipulating the belowground separation between competitors. Plants were placed in pots with either a mesh barrier that allowed the passage of hyphae but not roots, a solid barrier that prevented passage of hyphae and roots, or no barrier (full intermingling of roots and hyphae) between them. Comparison of plant growth in pots with the mesh divider with the other treatments allowed me to delineate the effects of network formation and root competition on invasive plant performance. I found that invasive plants generally had increased size and biomass without arbuscular mycorrhizal fungi (AMF) present compared to without. However, with AMF, invasives grown in pots with a mesh divider performed superiorly to invasives in solid and 'no barrier' treatments, suggesting importance of hyphal interactions. Invasive plant performance was poorest when no barrier was present, suggesting that the intensity of root competition may affect invasion success. The level of mycorrhizal colonization was not significantly correlated with host growth; however, the presence/absence of mycorrhizae did affect plant performance and competition, through exacerbating size differences between competing plants. Mycorrhizal presence generally 
reduced shoot nitrogen and phosphorus content, but invasive plant shoot nitrogen content was higher in mycorrhizal plants than non-mycorrhizal in the mesh barrier treatment, suggesting CMN influences on plant nutrient status.

\section{Keywords}

CMNs (common mycelial networks); AMF (arbuscular mycorrhizal fungi); competition; invasion ecology; invasive plants; resource sharing

\section{Introduction}

Resource sharing may be as important to the structure and diversity of plant communities as resource competition (Kytoviita et al. 2003). The sharing of resources can happen directly through processes such as plant root exudation (Inderjit and Weiner 2001, Bais et al. 2006), hydraulic lift (Caldwell et al. 1998), and hyphal networks formed by arbuscular mycorrhizal fungi (AMF) (Mikkelsen et al. 2008). How and to what extent plants share resources can affect plant growth and community composition. For example, resource sharing and interactive effects of resource sharing and competition can help structure plant communities and influence future species distributions (Leake et al. 2004). For invasive plant communities, determining the effects of resource sharing on ecological processes is crucial, as it could impact the establishment, success and spread of invasive plants (Kuebbing et al. 2012). This study examines the effects of resource sharing through common mycelial networks formed by AMF on competitive interactions of the newly invasive bunchgrass Brachypodium sylvaticum.

Arbuscular mycorrhizal fungi (AMF) are obligate fungal symbionts that colonize plant roots and utilize host photosynthates in exchange for increasing nutrient and water availability to the plant. AMF can form hyphal networks, termed common mycelial 
networks (CMNs), connecting plants (Smith and Read 2008) and serving as physical linkages for resource exchange. CMNs are capable of transferring carbon (Robinson and Fitter 1999, Carey et al. 2004), nutrients (Zabinski et al. 2002, Von Thun 2013), water (Egerton-Warburton et al. 2007), allelopathic chemicals (Barto et al. 2011), metabolites and defense signals between plants (Song et al. 2010). Contributing to network expansion and connectedness are hyphal fusions (anastomoses) that occur among self or genetically similar fungal cells (Selosse et al. 2006). Although plant-plant nutrient and carbon transfer through CMNs connecting similarly sized plants is likely not of a high enough magnitude to exert ecological-scale impacts (Simard and Durall 2004, Wilson et al. 2006), the sharing of a given resource pool between networked plants and differential mycorrhizal allocation to connected hosts may affect plant community ecology (Kytoviita et al. 2003, Selosse et al. 2006).

Common mycelial networks can mediate interactions amongst connected plants (Selosse et al. 2006, Weremijewicz and Janos 2013). Early work suggested AMFmediated resource transfer was powered by a resource concentration gradient established between competitively superior and subordinate species (Grime et al. 1987, Hart et al. 2003). It was postulated that if multiple AMF-linked plants disproportionally acquire nutrients from a shared fungus, then that resource concentration gradient would act to shuttle nutrients from the partner with the higher rate of nutrient uptake to the partner with the lower rate. CMNs initially formed by larger neighbors have been found to facilitate seedling establishment and growth, potentially through this same postulated concentration gradient (van der Heijden 2004). However, recent research has found evidence of sophisticated fungal-host resource exchange mechanisms, with the fungi able 
to preferentially allocate shared resources to the networked plants providing a higher carbon sink (Lekberg et al. 2010, Kiers et al. 2011). This preferential allocation may explain why size inequality between competing conspecifics has been amplified (Weremijewicz and Janos 2013) and seedling growth has been suppressed by CMN formation in the presence of larger neighbors (Kytoviita et al. 2003). Variable CMN effects on plant success could also be attributed to plant and fungal identity, as well as plant age and growth stage.

Interestingly, multiple experiments examining invasive plant competition with a binary mycorrhizal presence/absence manipulation yielded unexpected results indicative of CMN influence. For example, the invasive species Centaurea melitensis was larger when grown in competition than when grown alone, but only with AMF present (Callaway et al. 2001), suggesting a direct invasive plant benefit from CMN formation through "mycorrhizal-mediated parasitism" (Callaway et al. 2001, Bray et al. 2003). Similarly, results from my previous experiment using Brachypodium sylvaticum (Workman, in prep) showed an increase in invasive plant performance when grown with natives, but not with conspecifics, and only with AMF present. In other words, there was a greater difference in intra- and interspecific competition with AMF infection than in sterile soil. I suspected this effect to be due to mycorrhizal mediated parasitism through $\mathrm{CMN}$ formation; however, $\mathrm{CMN}$-mediation of competitive outcomeswas not directly tested. In fact, it has yet to be shown that CMNs are ecologically significant in the context of altering invasive-native competitive interactions. Although CMN interactions are complex and context-dependent, their ubiquity and potential significance in plant invasion ecology merits closer study and using manipulative experiments. 
Here, I investigated the relationship between CMN formation and performance and competitive dynamics of the invasive grass Brachypodium sylvaticum (slender false brome). B. sylvaticum is a newly invasive bunchgrass found in high densities primarily throughout the Northwestern United States, where it has been rapidly spreading since the 1980s (Rosenthal et al. 2008). B. sylvaticum is native to Eurasia and North Africa, where it is widely distributed along elevation and light availability gradients. It is listed as a quarantined invasive species in California, Washington, and Oregon, USA (CDFA 2013; NWCB 2013; ODA 2013), and has also been sighted in low abundance on the east coast of North America (Roy et al. 2011). B. sylvaticum forms dense monocultures, typically under forest canopies, leading to a decrease in herbaceous diversity and an alteration in forest fire dynamics through the prevention of tree seedling germination (Holmes et al. 2010, Roy et al. 2011). False brome is ideal for use in this study, as its performance and competitive ability has already been found to be influenced by mycorrhizal colonization (Workman, unpublished data). Understanding the mechanisms underlying this differential interaction is important for predicting outcomes of B. sylvaticum competition with native competitors and conspecifics, and to what degree this is influenced by CMN formation.

In this study, I asked if common mycelial network formation would differentially impact invasive plant competition with both conspecifics and native competitors. CMN formation and root interactions were manipulated by the insertion of mesh or solid barriers between competing plants. If resource sharing through CMNs was found increase contrasts in effective resource levels between competitors (indicated by heightened competitive asymmetry in plants with a mesh barrier between them with AMF relative to those without), and if this effect was different between invasive and native neighbors, this 
would support the hypothesis that CMNs contribute to shaping invasive success and plant community structure.

\section{Methods}

Seeds of Brachypodium sylvaticum and its native competitor Bromus vulgaris (Columbia brome) were collected from several sites within Milo McIver State Park, Estacada, Oregon in October 2012. B.sylvaticum within Milo McIver are distributed along elevational, moisture and light gradients (Taylor, in review) ranging from dry(er) upland coniferous forests to riparian habitats and deciduous lowland forests. The native competitor Bromus vulgaris (Columbia brome) was chosen due to its similar environmental preference and proximity to B. sylvaticum within the majority of sites sampled. Whole field soil was collected from an open grassland outside of Milo McIver and used to establish pot cultures eight months prior to experimental initiation. Spore extractions were performed to ensure mycorrhizal spore presence and diversity. Pot cultures were established with Sorghum bicolor, and were harvested and repotted once every two months (for a total of 4 times) to stimulate spore propagation.

To examine the effects of common mycelial network formation on competitive interactions, B. sylvaticum and B. vulgaris were grown in mixture and monoculture, with or without mycorrhizae, in pots partitioned by either a solid barrier, fine mesh barrier, or no barrier. The solid divider (Poly-Cover plastic sheeting, $0.75 \mathrm{~mm}$ thickness, Warp Bros, Chicago, IL) served to block root interactions as well as CMN formation and eliminate belowground competition. The 38 um nylon mesh screen barrier (Sefar, Depew, NY, USA) allowed for CMN formation while eliminating root interactions. The no divider (full interaction) treatment allowed for both $\mathrm{CMN}$ formation and root interactions. By 
comparing competitive intensity between plants grown in pots with a solid divider and a mesh divider, mycorrhizal network effects were isolated without the confounding influence of root interactions.

The efficacy of the 38 um mesh pot design in allowing CMN formation while blocking root interactions was tested in a pilot experiment. This was achieved by inoculating both plants on either side of the mesh, one with $50 \mathrm{~mL}$ whole field soil inoculum containing mycorrhizal spores, and one with $50 \mathrm{~mL}$ sterilized (doubly autoclaved) whole field soil inoculum. After a 60 day growth period spanning June and July 2013, plants were harvested. Both plants were found to be colonized in $83 \%(10 / 12)$ of the pots. The two non-colonized were attributed to low initial spore density in those pots, as the inoculated side of the pot was also found to be non-colonized. This same halfinoculation method was used to establish controls at the beginning of this experiment. This ensured that mycorrhizal networks were capable of establishing through the mesh barrier within the short time period examined.

In my greenhouse experiment, two plants were included in each pot (TP49, Steuwe and Sons, Corvallis OR). All pots contained 30:70 sand:potting soil mix. Plants were either designated as a "target" or "neighbor" plant, with an invasive always being the target and either a native or invasive being the neighbor. In intraspecific pairings, a coin was flipped to determine which of the two invasives would be the target and which would be the neighbor. Fourteen-day-old seedlings from eight invasive maternal families were used, and all maternal families were randomly represented across treatments. Three native plant maternal families were used, and ten-day old seedlings were randomly represented across treatments. Plants were potted in NW and SE corners of each pot 
roughly $7 \mathrm{~cm}$ apart, and the target and neighbor position (NW or SE) was randomized by coin flip.

Both plants in each pot received a 50 g plug of soil taken from established mycorrhizal trap cultures containing AMF spores. Spore extractions 50 g samples revealed an average of $92 \pm 28(\mathrm{~N}=6)$ spores per plug. Each plug also contained small root fragments from the sorghum in pot cultures. Sterile controls for each plant pairing and each pot design received $50 \mathrm{~g}$ of doubly autoclaved soil (60 minutes, 121 degrees $\mathrm{C}$, two cycles 24 hours apart). By comparing plants grown in sterile soil in pots with the solid and with no divider, the relative intensity of root and shoot competition was determined without the confounding influence of AMF. A control with mesh and no AMF was included to eliminate potential effects of mesh screen presence on plant performance.

To mimic the dynamics of nutrient availability in the field and to reduce the potential negative effects of using a limited soil volume, all plants were treated with a nitrogen and phosphorous fertilizer at the beginning of the experiment. Starting nutrient availability was slightly higher for sterile treatments $\left(42 \mathrm{ppm} \mathrm{H}_{2} \mathrm{PO}_{4}^{-}, 29 \mathrm{ppm} \mathrm{NaHCO} 3-\right.$ P, 102 ppm K, 283 ppm Mg, 1087 ppm Ca, 37 ppm Na, 73 ppm N) than for nonsterile treatments (38 ppm P1, 25 ppm NaHCO3-P, 118 ppm K, 329 ppm Mg, 1320 ppm Ca, 40 ppm Na, $52 \mathrm{ppm} \mathrm{N}$ ) due to a nutrient flush accompanying sand and inoculum sterilization. This was taken into account during data analysis and interpretation.

The growth period in the greenhouse was 60 days, as determined to be optimal for both allowance of mycorrhizal infection and avoidance of plant root-boundedness. Height and tiller number measurements were taken at initial transplant date (day 0), 15, 30, 45, 
and 60 days (harvest day). Upon destructive harvest at day 60 , roots and shoots were separated, dried, and weighed. Sub-samplings of roots were taken, cleared and stained (Koske and Gemma 1989) and mounted on slides to be assessed for degree of mycorrhizal colonization (McGonigle et al. 1990).This was done for all inoculated plants, for the sterile controls a random subsampling of roots were examined $(n=25)$ to ensure no mycorrhizal colonization in the sterile treatments.

Plant tissue nutrient analyses were performed post-harvest to determine if shoot nutrient content within target plants varied depending on barrier type, neighbor identity, presence/absence of mycorrhizae and presence/absence of CMN formation. Plant growth measures alone were indicative of competitive intensity, but determination of differential nutrient assimilation between plants in different treatments was essential for determining the AMF and CMN impacts. Dried shoot tissues (whole tops provided) for 6 target plants within each treatment $(\mathrm{N}=72)$ were prepared for nutrient analysis by 500 degree $\mathrm{C}$ incineration for 5 hours followed by digestion in 2M HCl. Percent $\mathrm{N}, \mathrm{P}, \mathrm{K}, \mathrm{Ca}, \mathrm{Mg}, \mathrm{Mn}$, $\mathrm{Fe}, \mathrm{Cu}, \mathrm{B}, \mathrm{Al}, \mathrm{Zn}$, and $\mathrm{Na}$ were analyzed by inductively coupled plasma atomic emission spectrometry analysis and standardized by dry weight at Pennsylvania State University (http://agsci.psu.edu).

\section{Statistical analysis}

The intensity of plant competition was quantified using neighbor plant size as a covariate in an ANCOVA model, with invasive target plant performance indicators (shoot dry mass, root dry mass, size at harvest) as response variables. In this way we were able to directly enumerate the impact of competitor characteristics (root and shoot dry mass, size, etc) on invasive plant success (qualified by biomass, size, and nutrient 
status). Barrier type, neighbor identity and mycorrhizal inoculation were included as fixed effects, block was included as a random effect, and initial target size and chlorophyll content were included as covariates.

Effects of mycorrhizal infection presence/absence, neighbor identity (native or invasive), barrier type (solid, mesh, or no barrier) and their interactions on shoot tissue nutrient content $(\mathrm{N}, \mathrm{P}, \mathrm{K})$ were quantified in a three-way ANOVA. Data were analyzed in SAS 9.2 (SAS Institute Inc, Cary, NC, USA).

\section{Results}

Invasive target plant size, total biomass, and root dry mass (RDM) were all negatively impacted by mycorrhizal colonization. Size decreased by $21 \%$, biomass by $17 \%$ and root dry mass by $27 \%$, significant at $\mathrm{p}=0.0047,0.03,0.03$ for each effect, respectively (Table 2.1), for plants grown with AMF.

Barrier type affected total biomass and root dry mass, and was interactive with AMF presence for RDM. With AMF absent, invasive RDM was $29 \%$ higher in the solid barrier treatment than either the mesh or 'no barrier' treatment, which were not significantly different (Figure 2.2). However, with AMF present, RDM measures were different between treatments, with the mesh barrier having 37\% higher RDM than 'no barrier' treatment, and the solid barrier lying between the two (Figure 2.2).

Competitive indices constructed using RDM revealed a 3.8-fold difference between index measures for invasive plants grown with invasive and native neighbors without AMF present. However, with AMF present, index measures were not only negative (meaning average RDM for that treatment fell below the mean RDM for all treatments), but they were much more similar between competitors, with only a 0.4 -fold, 
insignificant difference between them (Figure 2.3a). However, when competitive indices were parsed out by neighbor identity and barrier type, it was found that invasive plants grown with no barrier between them and the competitor had a much lower index value than either the mesh or solid barriers, and no real difference between index values for competitors was found (Figure 2.3b).

Nitrogen, phosphorus and potassium levels in shoots of subsampled invasive target plants were all impacted by experimental manipulations (Table 2.2). The shoot nitrogen content (standardized by dry mass) was lowered by $9 \%$ by AMF colonization when a native neighbor was present, by increased by $9 \%$ by AMF colonization when an invasive neighbor was present (Figure 2.4). An AMF by barrier interaction was also found, with plants grown in the solid barrier treatment having the lowest $\mathrm{N}$ content with no AMF present, but the same $\mathrm{N}$ content as plants grown in the mesh treatment with AMF present. With AMF present, plants grown in the 'no barrier' treatment had the highest $\mathrm{N}$ content by $18 \%$ (Figure 2.5a). $\mathrm{P}$ content was affected differently than $\mathrm{N}$ content by barrier treatment. P levels were highest in the 'no barrier' treatment, lower in the mesh barrier treatment, and lowest in the solid barrier treatment (Figure 2.5b). N levels were highest in the mesh barrier treatment, lower in the 'no barrier' treatment, and lower, but not significantly, in the solid barrier treatment (Figure 2.5a).

Mycorrhizal colonization percentages averaged $21.09 \pm 1.51 \%$ for inoculated target plants, $20.6 \pm 1.61 \%$ for invasive neighbors, and $11.03 \pm 1.35 \%$ for native neighbors. Barrier treatment did not affect the quantity of AMF colonization. The random subset $(\mathrm{n}=25)$ of plants grown in sterile soil was found to be absent of mycorrhizal colonization. 


\section{Discussion}

Growth of invasive grass Brachypodium sylvaticum was impacted by common mycelial network (CMN) formation by arbuscular mycorrhizal fungi (AMF). Effects of CMN formation were evidenced by the enhanced shoot and root growth of B. sylvaticum in the mesh barrier treatment relative to other barrier treatments with AMF, which was not found in the nonmycorrhizal controls. Nutrient analysis results also supported CMN effects, as plants grown in in the mesh barrier treatment had significantly higher $\mathrm{N}$ and $\mathrm{P}$ content than the solid barrier analog.

The equivalency of plant growth variables (RDM, SDM, and size) in the mesh barrier treatment between $+/-$ AMF treatments, but not in the solid or 'no barrier' treatments suggests common mycelial network influence. As these growth variables were all significantly lower with AMF in the solid and 'no barrier' treatments, it is possible that in the mesh treatment hyphal networks are acting to shuttle resources from the neighboring plant to the invasive target. Several studies have found evidence that nutrient transfer between connected plants could be of a high enough magnitude to significantly affect target plant growth (Zabinski et al. 2002, Walder et al. 2012). However, no decrease in neighbor size was noted in the mesh barrier treatment relative to other treatments, suggesting that if resource acquisition by invasive target plants was occurring, it was not to the detriment of the neighbor. However, this could have been a result of adequate nutrient availability in the pots, and what was transferred between plants were "luxury goods", or resources not limited in neighboring plants (Walder et al. 2012). Further studies manipulating nutrient availability and carried out under a longer growing 
season would elucidate the roles of nutrient stress and plant age on the invasive growth enhancement seen with AMF in the mesh barrier treatment.

The plant tissue nutrient analysis revealed that barrier type, mycorrhizae, and an interaction of the two differentially impacted nitrogen and phosphorus content in shoot tissue. The presence of AMF decreasing P presence in leaf tissue (in all barrier treatments) was surprising, as mycorrhizae typically make forms of $\mathrm{P}$ available for plant uptake that would not otherwise be utilized (Grimoldi et al. 2005, Smith and Read 2008). However, it is possible that mycorrhizal colonization downregulated the production of phosphate transporters in the host plant, and that the "snapshot" seen at harvest date was indicative of the point prior to when benefit began to manifest (Burleigh 2001, Grace et al. 2009, Smith et al. 2009). It is also possible that the CMNs are unevenly partitioning nutrients to competitors who were not measured in the nutrient analysis, or that nutrients are being retained within plant roots, but further nutrient testing would need to be done to address this question.

Shoot $\mathrm{N}$ content was differentially affected than $\mathrm{P}$, with higher $\mathrm{N}$ found in $\mathrm{AM}$ plants in the 'no barrier' treatment relative to non-AM, and the opposite result in the mesh barrier treatment, with no difference between AM and NM plants in the solid barrier pots. It is possible that in the absence of root competitive interactions induced in the mesh and solid barrier treatments, AMF are competing with plants for $\mathrm{N}$, as has been shown in previous studies (Smith et al. 2009). However, if there were N competition occurring between plants and fungi, reduced $\mathrm{N}$ content would be expected with AMF, compared to non-AM plants, in all barrier treatments. On the contrary, no difference in leaf $\mathrm{N}$ content between $\mathrm{AM}$ and NM plants in the solid barrier treatment was found, 
suggesting that degree of belowground competition interacts with AMF presence to affect shoot $\mathrm{N}$ status.

Neighbor identity (invasive or native) affected the success of the invasive target plant. Target plant growth was positively affected by native neighbors but neutrally by conspecifics. This result is consistent with a past experiment with B. sylvaticum, which found that invasive plant growth was stunted by pairing with conspecifics relative to pairing with natives (Workman, unpublished data). It is interesting that no significant adverse effects of neighbor (both invasive and native) size were found on invasive target size in any treatment, although this could be due again to adequate nutrient availability. Because growth period was short and a small amount of fertilizer was added at the beginning of the experiment, the plants in this experiment may not be experiencing the negative growth consequences of competition because they had sufficient space and nutrients.

The degree of mycorrhizal colonization was significantly lower in native neighbor plants than in invasives. This was unexpected, as it has been predicted that invasive plants have lower mycorrhizal dependence than natives, and thus would be more likely to exhibit reduced colonization (Busby et al. 2011, Jordan et al. 2012). However, in this experiment, the AMF communities did not appear to benefit either grass species, so perhaps a lower colonization was to the benefit of the native competitor. Additionally, AMF colonization did not correlate with any plant performance variables for either plant species in any barrier treatments, therefore the lower colonization in natives appears to not have any growth affects. It is possible that percent mycorrhizal colonization does not correlate with plant growth response merely due to the low degree of colonization. Also, 
microscopy methods of quantifying mycorrhizal abundance has limitations and does not predict total AMF equally well for all mycorrhizal families (Hart and Reader 2002). Therefore, studies including total hyphal extractions and quantifying spore abundances in soil between treatments would elucidate whether there is a closer correlation between AMF colonization and plant growth.

Resource sharing and competition between cohabitating plants is affected by AMF presence, possibly through common mycelial network formation. CMN formation could be a mechanism for invasive plant success in the field. Although AMF presence generally negatively affects invasive growth, the negative growth affects are alleviated in the presence of hyphal network formation and in the absence of root competition. Considering that AMF are essentially ubiquitous in the field, it is likely that hyphal networks between competing plants could be shifting the balance of competition through differentially allocating the available resource pool.

\section{Concluding remarks and future directions}

My studies were the first to examine both differential impacts of invaded and noninvaded range AMF inocula and direct impacts of common mycelial network formation on invasive plant intra- and interspecific competition. My first study elucidated that AMF in both ranges are capable of exerting effects that can influence the maintenance of native communities and invasion dynamics. My second study then found that common mycelial network formation by AMF could be a potential mechanism for the competitive alteration observed in the first study.

Understanding the ecological significance of common mycelial network formation on invasive plant performance and competition is important in determining 
fungal influences on invasive success and spread. Because CMN formation altered nutrient availability in competing plants in as little as 60 days, it is likely that long-lived perennial plants could be even more highly affected by these hyphal networks, which could influence invasion success and persistence.

Future studies could combine components of both experiments to assess whether CMN effects observed in study two would be consistent for both invaded and noninvaded range AMF communities. Additionally, parsing out the impacts of other soil biota such as bacteria and other fungi could elucidate whether effects are solely due to AMF. Isolating soil samples from many invaded and noninvaded ranges could also be useful in determining presence and strength of site-specific effects, and whether the results found in study one are consistent across spatial scales.

This research could be implemented in managerial practices designed to halt or contain biological invasions. If AMF increase plant diversity in noninvaded environments by inducing negative feedbacks on cohabitating hosts, "buffing up" noninvaded ranges with natural mycorrhizal inoculum, or reduction of practices (agricultural, recreational, etc) which disturb environments and lower AMF diversity, would strengthen noninvaded ranges and halt invasive spread within. Utilizing natural biotic conditions to constrain rather than classical managerial processes that increase disturbance (such as herbicides, burning, mowing and weeding) could stop the vicious cycle of invasion that persists through these ecologically damaging management practices. 


\section{Acknowledgements}

Thank you to E. Webb and J. Elias for research assistance throughout the duration of this project. To labmates G. Marchini and C. Lee for comments and assistance. To H. Bhaskaran for help constructing pots, and M. Duveneck for assistance with R. To S. Eppley for comments. This work was supported by Portland State Department of Biology and a Forbes-Lea research grant awarded to Rachael Workman. 
Table 2.1: Analysis of plant growth responses to experimental manipulations.

Barrier treatment (mesh, solid, or no barrier), AMF inoculation (+/-) as fixed effects, and initial target size as a covariate, significantly affected invasive target plant performance. $\mathrm{F}$ values given, significance denoted $(* \mathrm{p}<0.05, * * \mathrm{p}<0.01, * * * \mathrm{p}<0.001)$.

\begin{tabular}{cccccc}
\hline \hline Effect & df & $\begin{array}{c}\text { Total } \\
\text { biomass } \\
(\mathrm{g})\end{array}$ & $\begin{array}{c}\text { Shoot dry mass } \\
(\mathrm{g})\end{array}$ & $\begin{array}{c}\text { Root dry mass } \\
(\mathrm{g})\end{array}$ & $\begin{array}{c}\text { Size at } \\
\text { harvest }(\mathrm{cm})\end{array}$ \\
\hline Block & 11 & $\mathbf{2 . 8 6 * *}$ & $\mathbf{2 . 5 1 * *}$ & $\mathbf{2 . 1 5 *}$ & 1.7 \\
Barrier & 2 & $\mathbf{3 . 2 8}^{*}$ & 1.17 & $\mathbf{6 . 2 1 * *}$ & 0.08 \\
AMF & 1 & $\mathbf{5 . 2 9 *}$ & 2.38 & $\mathbf{5 . 3 4 *}$ & $\mathbf{1 1 . 6 7 * * *}$ \\
Neighbor ID & 1 & 0.8 & 0.46 & 0.01 & 0.44 \\
Barrier*AMF & 2 & 1.24 & 1.81 & 0.87 & $\mathbf{4 . 2 3 *}$ \\
NeighID*Barrier & 2 & 0.87 & 1.02 & 0.37 & 0.3 \\
NeighID*AMF & 1 & 0.06 & 0.35 & 1.68 & 1.31 \\
Neigh*Bar*AMF & 2 & 0.42 & 0.19 & 0.93 & 0.53 \\
Initial size & 1 & $\mathbf{1 3 . 0 1 * * *}$ & $\mathbf{7 . 5 4 * *}$ & $\mathbf{9 . 3 8 * *}$ & $\mathbf{5 . 5 4 *}$ \\
\hline \hline
\end{tabular}


Table 2.2: Analysis of invasive plant shoot nutrient status in response to experimental manipulations.

Shoot nutrient content (all measures in \% nutrient/shoot dry weight) of invasive target plants was significantly affected by barrier treatment (solid, mesh, or no barrier), neighbor identity (native or invasive), mycorrhizal infection $(+/-)$, and some of their interactions. F values given, significance denoted $(* \mathrm{p}<0.05, * * \mathrm{p}<0.01, * * * \mathrm{p}<0.001)$.

\begin{tabular}{ccccc}
\hline \hline Effect & df & $\mathrm{N}$ & $\mathrm{P}$ & $\mathrm{K}$ \\
\hline Barrier & 2 & $\mathbf{4 . 5 2 *}$ & $\mathbf{7 . 4 0 * *}$ & 1.99 \\
Neighbor ID & 1 & 0.38 & 0.01 & 0.38 \\
AMF & 1 & 0.02 & $\mathbf{2 7 . 8 9 * * *}$ & $\mathbf{6 . 7 2 *}$ \\
Barrier*AMF & 2 & $\mathbf{3 . 5 5 *}$ & 2.7 & 1.25 \\
NeighID*Barrier & 2 & 1.57 & 0.15 & 0.67 \\
NeighID*AMF & 1 & $\mathbf{7 . 8 9 * *}$ & 0.06 & 1.33 \\
Neigh*Bar*AMF & 2 & 1.85 & 1.46 & 0.67 \\
\hline \hline
\end{tabular}


Figure 2.1: Sample block design containing all combinations of experimental treatments. Plant pairings are designated by letters ( $\mathrm{II}=$ invasive-invasive intraspecific pairings; $\mathrm{IN}=$ invasive-native interspecific pairings), barrier types are given by transect lines (solid = solid barrier; dashed $=$ mesh barrier; none $=$ full interactions pots), and mycorrhizal presence/absence is given by color (purple, live, + AMF; blue, sterile, -AMF).

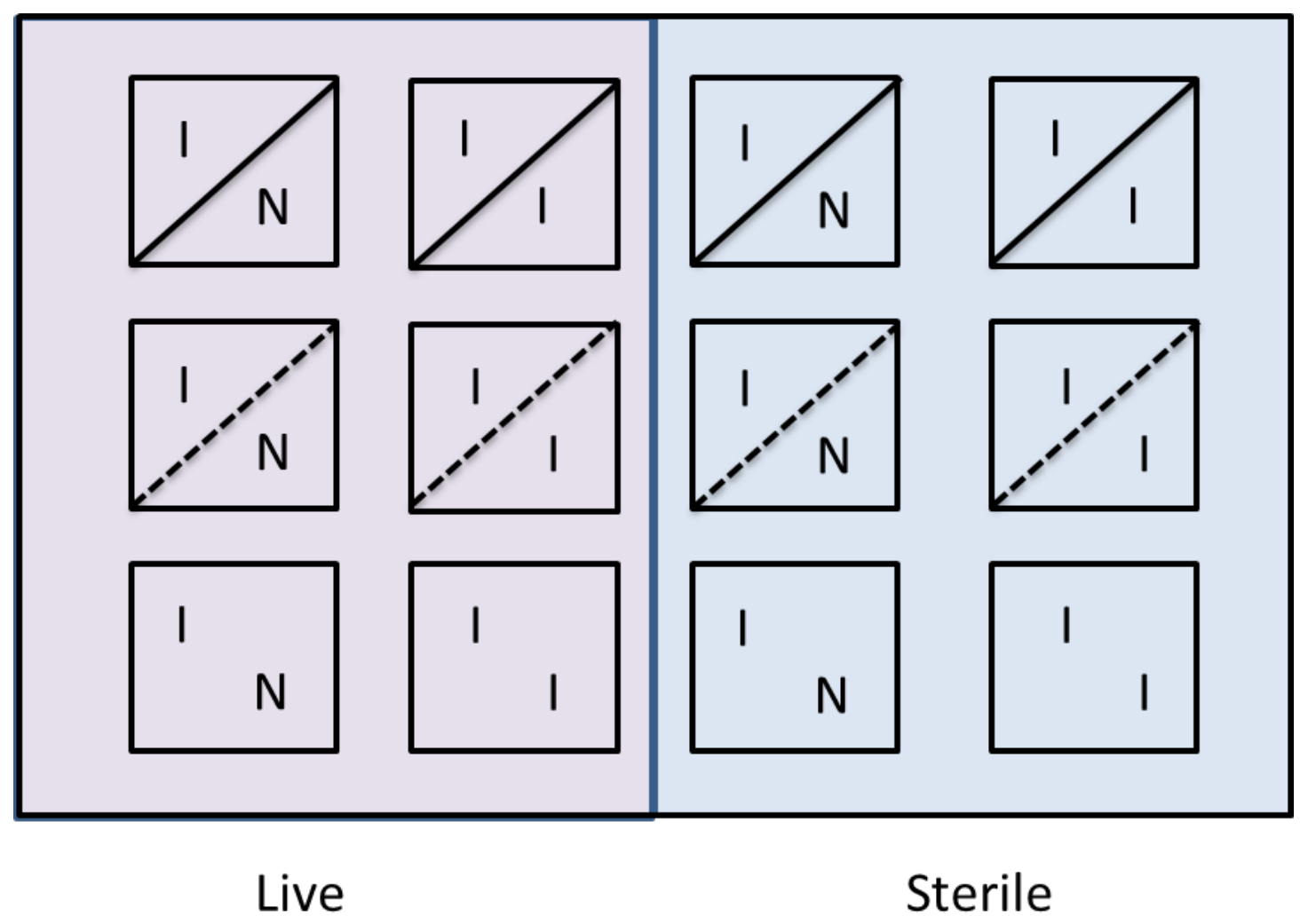


Figure 2.2: Effects of barrier type and AMF on invasive plant growth.

Barrier type impacted root dry mass (RDM; g) and shoot dry mass (SDM; g) differently for plants colonized by AMF than those not colonized. Means given by bars, lines represent SE. Lowercase letters denote significant differences between barrier treatments, determined by Tukey's posthoc. Asterisks designate significant differences between plants grown with and without AMF.
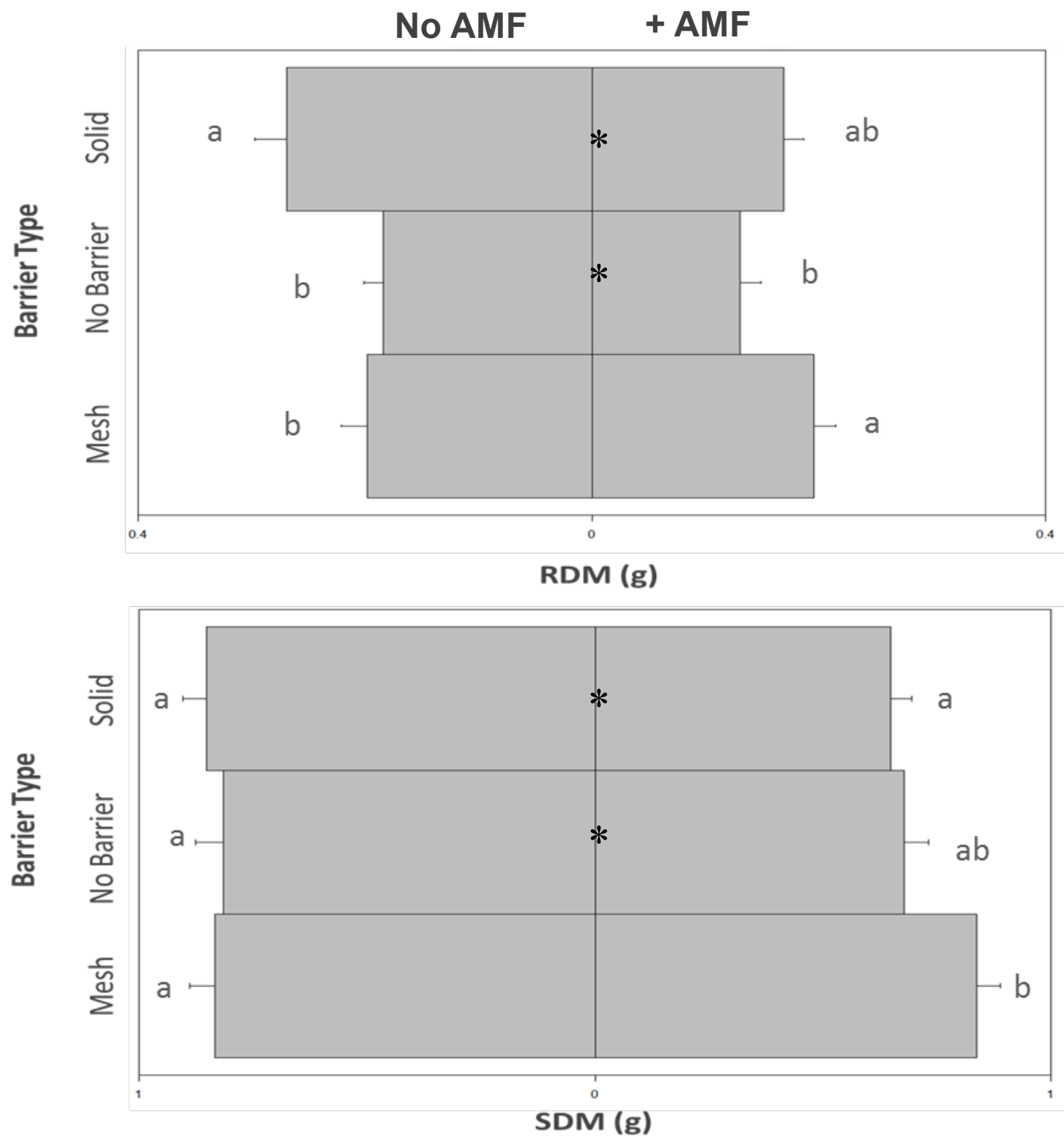
Figure 2.3: Effects of AMF, neighbor and barrier type on competitive index measures. Competitive indices (mean $\pm \mathrm{SE}$ ) of target invasive species, sorted by neighbor identity (invasive or native plant) and influenced by both AMF presence and barrier type.

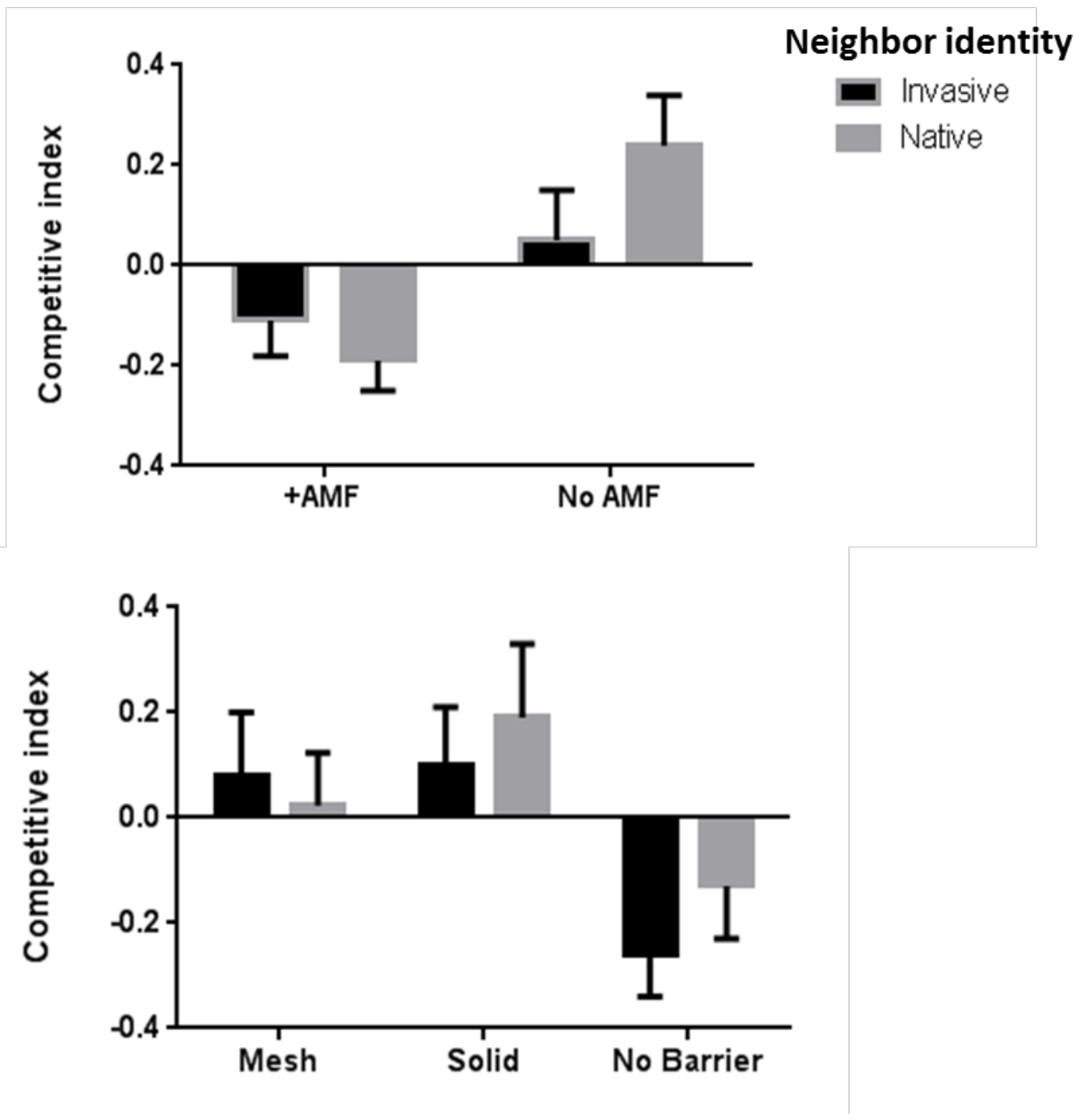


Figure 2.4: Interactive effects of mycorrhizal inoculation and barrier treatment on invasive plant growth and nutrient status.

Neighbor identity and barrier type interacted with AMF presence to affect shoot nitrogen content (mean $\pm \mathrm{SE})$.

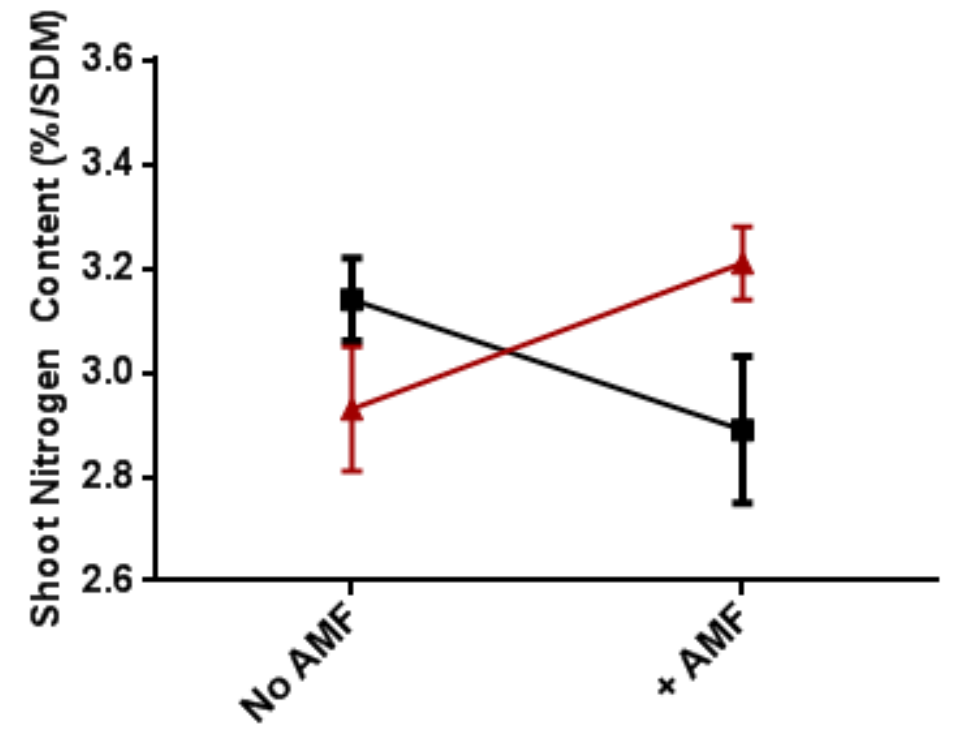

\section{Neighbor identity}

$\rightarrow$ Native

$\leftarrow$ Invasive 
Figure 2.5. Effects of barrier type on target invasive shoot nitrogen and phosphorus content.

Means given, error bars represent standard error. Asterisk denote significant differences within barrier treatment, between plants grown with and without AMF.

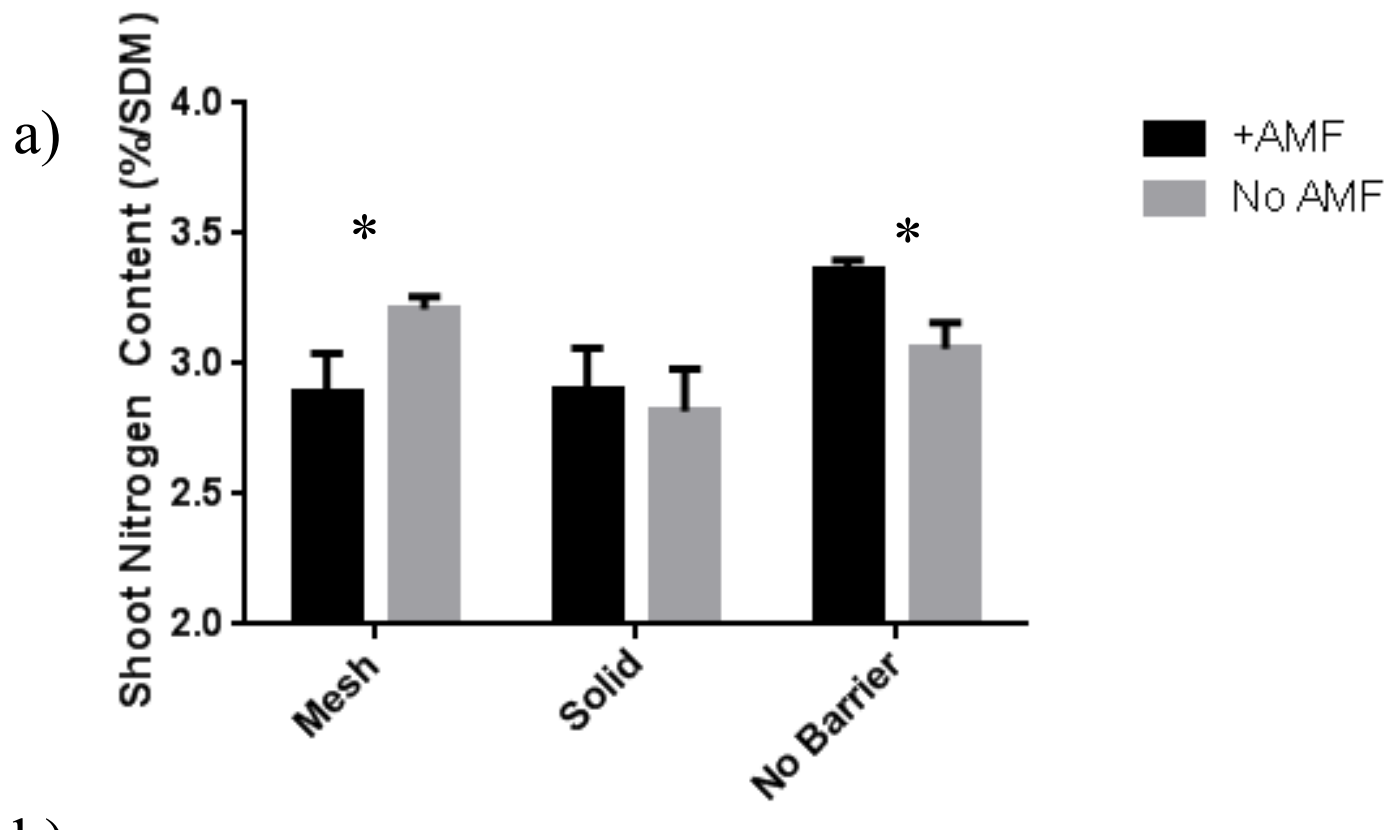

b)

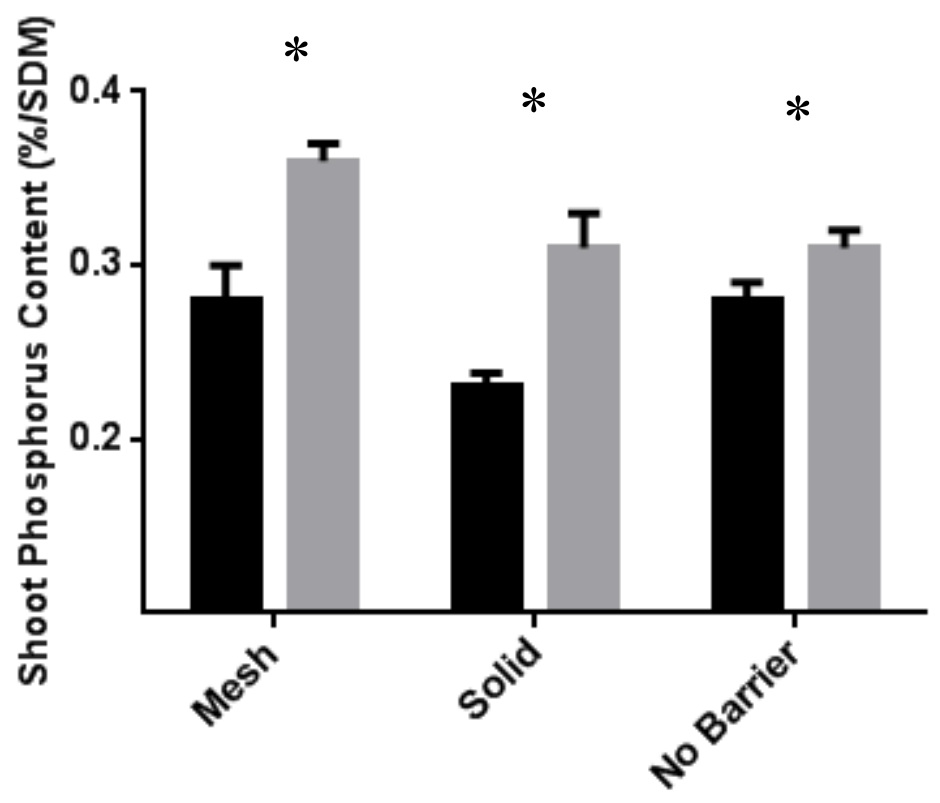

Barrier Treatment 


\section{Literature cited}

Auge, R. M. 2001. Water relations, drought and vesicular-arbuscular mycorrhizal symbiosis. Mycorrhiza 11:3-42.

Bais, H. P., T. L. Weir, L. G. Perry, S. Gilroy, and J. M. Vivanco. 2006. The role of root exudates in rhizosphere interations with plants and other organisms. Annual Review of Plant Biology 57:233-266.

Barto, E. K., M. Hilker, F. Mueller, B. K. Mohney, J. D. Weidenhamer, and M. C. Rillig. 2011. The Fungal Fast Lane: Common Mycorrhizal Networks Extend Bioactive Zones of Allelochemicals in Soils. Plos One 6.

Bever, J. D., P. A. Schultz, A. Pringle, and J. B. Morton. 2001. Arbuscular mycorrhizal fungi: More diverse than meets the eye, and the ecological tale of why. Bioscience 51:923-931.

Bever, J. D., K. M. Westover, and J. Antonovics. 1997. Incorporating the soil community into plant population dynamics: the utility of the feedback approach. Journal of Ecology 85:561-573.

Bray, S. R., K. Kitajima, and D. M. Sylvia. 2003. Mycorrhizae differentially alter growth, physiology, and competitive ability of an invasive shrub. Ecological Applications 13:565-574.

Burleigh, S. H. 2001. Relative quantitative RT-PCR to study the expression of plant nutrient transporters in arbuscular mycorrhizas. Plant Science (Shannon) 160:899904.

Busby, R., M. Stromberger, M. Denight, D. Gebhart, G. Rodriguez, and M. Paschke. 2011. Arbuscular mycorrhizal fungi diversity associated with coexisting cheatgrass and big sagebrush communities. Phytopathology 101:S23-S23.

Caldwell, M. M., T. E. Dawson, and J. H. Richards. 1998. Hydraulic lift: Consequences of water efflux from the roots of plants. Oecologia 113:151-161.

Callaway, R. M., B. Newingham, C. A. Zabinski, and B. E. Mahall. 2001. Compensatory growth and competitive ability of an invasive weed are enhanced by soil fungi and native neighbours. Ecology Letters 4:429-433.

Cameron, D. D., A. L. Neal, S. C. M. van Wees, and J. Ton. 2013. Mycorrhiza-induced resistance: more than the sum of its parts? Trends in Plant Science 18:539-545.

Carey, E. V., M. J. Marler, and R. M. Callaway. 2004. Mycorrhizae transfer carbon from a native grass to an invasive weed: evidence from stable isotopes and physiology. Plant Ecology 172:133-141.

Casper, B. B. and J. P. Castelli. 2007. Evaluating plant-soil feedback together with competition in a serpentine grassland. Ecology Letters 10:394-400.

Chapin, F. S. I., O. E. Sala, I. C. Burke, J. P. Grime, D. U. Hooper, W. K. Lauenroth, A. Lombard, H. A. Mooney, A. R. Mosier, S. Naeem, S. W. Pacala, J. Roy, W. L. Steffen, and D. Tilman. 1998. Ecosystem consequences of changing biodiversity. Bioscience 48:45-52.

Colautti, R. I., A. Ricciardi, I. A. Grigorovich, and H. J. MacIsaac. 2004. Is invasion success explained by the enemy release hypothesis? Ecology Letters 7:721-733. 
Cui, Q. G. and W. M. He. 2009. Soil biota, but not soil nutrients, facilitate the invasion of Bidens pilosa relative to a native species Saussurea deltoidea. Weed Research 49:201-206.

Davies, K. W. and T. J. Svejcar. 2008. Comparison of Medusahead-Invaded and Noninvaded Wyoming Big Sagebrush Steppe in Southeastern Oregon. Rangeland Ecology \& Management 61:623-629.

Egerton-Warburton, L. M., J. I. Querejeta, and M. F. Allen. 2007. Common mycorrhizal networks provide a potential pathway for the transfer of hydraulically lifted water between plants. Journal of Experimental Botany 58:1473-1483.

Evelin, H., R. Kapoor, and B. Giri. 2009. Arbuscular mycorrhizal fungi in alleviation of salt stress: a review. Annals of Botany 104:1263-1280.

Facelli, E., S. E. Smith, and F. A. Smith. 2009. Mycorrhizal symbiosis - overview and new insights into roles of arbuscular mycorrhizas in agro- and natural ecosystems. Australasian Plant Pathology 38:338-344.

Goodwin, J. 1992. The role of mycorrhizal fugi in competitive interactions among native bunchgrasses and alien weeds- a review and synthesis Northwest Science 66:251260.

Grace, E. J., O. Cotsaftis, M. Tester, F. A. Smith, and S. E. Smith. 2009. Arbuscular mycorrhizal inhibition of growth in barley cannot be attributed to extent of colonization, fungal phosphorus uptake or effects on expression of plant phosphate transporter genes. New Phytologist 181:938-949.

Grime, J. P., J. M. L. Mackey, S. H. Hillier, and D. J. Read. 1987. Floristic diversity in a model system using experimental microcosms. Nature 328:420-422.

Grimoldi, A. A., M. Kavanova, F. A. Lattanzi, and H. Schnyder. 2005. Phosphorus nutrition-mediated effects of arbuscular mycorrhiza on leaf morphology and carbon allocation in perennial ryegrass. New Phytologist 168:435-444.

Hall, C. A. S., J. A. Stanford, and F. R. Hauer. 1992. The distribution and abundance of organisms as a consequence of energy balances along multiple environmental gradients. Oikos 65:377-390.

Hart, M. M. and R. J. Reader. 2002. Does percent root length colonization and soil hyphal length reflect the extent of colonization for all AMF? Mycorrhiza 12:297301.

Hart, M. M., R. J. Reader, and J. N. Klironomos. 2003. Plant coexistence mediated by arbuscular mycorrhizal fungi. Trends in Ecology \& Evolution 18:418-423.

Hartnett, D. C., B. A. D. Hetrick, G. W. T. Wilson, and D. J. Gibson. 1993. Mycorrhizal influence on intraspecific and interspecific neighbor interactions amond coocuurring prairie grasses. Journal of Ecology 81:787-795.

Hawkes, C. V., J. Belnap, C. D'Antonio, and M. K. Firestone. 2006. Arbuscular mycorrhizal assemblages in native plant roots change in the presence of invasive exotic grasses. Plant and Soil 281:369-380.

Hetrick, B. A. D., G. W. T. Wilson, and C. E. Owensby. 1990. Mycorrhizal influences on big bluestem rhizome regrowth and clipping tolerance. Journal of Range Management 43:286-290.

Hildebrandt, U., M. Regvar, and H. Bothe. 2007. Arbuscular mycorrhiza and heavy metal tolerance. Phytochemistry 68:139-146. 
Hodge, A., T. Helgason, and A. H. Fitter. 2010. Nutritional ecology of arbuscular mycorrhizal fungi. Fungal Ecology 3:267-273.

Hoeksema, J. D., V. B. Chaudhary, C. A. Gehring, N. C. Johnson, J. Karst, R. T. Koide, A. Pringle, C. Zabinski, J. D. Bever, J. C. Moore, G. W. T. Wilson, J. N. Klironomos, and J. Umbanhowar. 2010. A meta-analysis of context-dependency in plant response to inoculation with mycorrhizal fungi. Ecology Letters 13:394407.

Holmes, S. E., B. A. Roy, J. P. Reed, and B. R. Johnson. 2010. Context-dependent pattern and process: the distribution and competitive dynamics of an invasive grass, Brachypodium sylvaticum. Biological Invasions 12:2303-2318.

Inderjit and J. Weiner. 2001. Plant allelochemical interference or soil chemical ecology? Perspectives in Plant Ecology Evolution and Systematics 4:3-12.

Jasper, D. A., L. K. Abbott, and A. D. Robson. 1991. The effect of soil disturbance on vesicular arbuscular mycorrhizal fungi in soils from different vegetation types. New Phytologist 118:471-476.

Johnson, N. C., J. H. Graham, and F. A. Smith. 1997. Functioning of mycorrhizal associations along the mutualism-parasitism continuum. New Phytologist 135:575-586.

Jordan, N. R., L. Aldrich-Wolfe, S. C. Huerd, D. L. Larson, and G. Muehlbauer. 2012. Soil-Occupancy Effects of Invasive and Native Grassland Plant Species on Composition and Diversity of Mycorrhizal Associations. Invasive Plant Science and Management 5:494-505.

Kiers, E. T., M. Duhamel, Y. Beesetty, J. A. Mensah, O. Franken, E. Verbruggen, C. R. Fellbaum, G. A. Kowalchuk, M. M. Hart, A. Bago, T. M. Palmer, S. A. West, P. Vandenkoornhuyse, J. Jansa, and H. Bucking. 2011. Reciprocal Rewards Stabilize Cooperation in the Mycorrhizal Symbiosis. Science 333:880-882.

Koske, R. E. and J. N. Gemma. 1989. A modified procedure for staining roots to detect VA-mycorrhizas. Mycological Research 92:486-505.

Kytoviita, M. M., M. Vestberg, and J. Tuom. 2003. A test of mutual aid in common mycorrhizal networks: Established vegetation negates benefit in seedlings. Ecology 84:898-906.

Leake, J. R., D. Johnson, D. P. Donnelly, G. E. Muckle, L. Boddy, and D. J. Read. 2004. Networks of power and influence: the role of mycorrhizal mycelium in controlling plant communities and agroecosystem functioning. Canadian Journal of Botany-Revue Canadienne De Botanique 82:1016-1045.

Lekberg, Y., E. C. Hammer, and P. A. Olsson. 2010. Plants as resource islands and storage units - adopting the mycocentric view of arbuscular mycorrhizal networks. Fems Microbiology Ecology 74:336-345.

Levine, J. M., P. B. Adler, and S. G. Yelenik. 2004. A meta-analysis of biotic resistance to exotic plant invasions. Ecology Letters 7:975-989.

Marler, M. J., C. A. Zabinski, and R. M. Callaway. 1999. Mycorrhizae indirectly enhance competitive effects of an invasive forb on a native bunchgrass. Ecology 80:11801186. 
McGonigle, T. P., M. H. Miller, D. G. Evans, G. L. Fairchild, and J. A. Swan. 1990. A new method which gives an objective measure of colonization of roots by vesicular arbuscular mycorrhizal fungi. New Phytologist 115:495-501.

Mikkelsen, B. L., S. Rosendahl, and I. Jakobsen. 2008. Underground resource allocation between individual networks of mycorrhizal fungi. New Phytologist 180:890-898.

Mitchell, C. E., A. A. Agrawal, J. D. Bever, G. S. Gilbert, R. A. Hufbauer, J. N. Klironomos, J. L. Maron, W. F. Morris, I. M. Parker, A. G. Power, E. W. Seabloom, M. E. Torchin, and D. P. Vazquez. 2006. Biotic interactions and plant invasions. Ecology Letters 9:726-740.

Moora, M. and M. Zobel. 1996. Effect of arbuscular mycorrhiza on inter- and intraspecific competition of two grassland species. Oecologia 108:79-84.

Mummey, D. L. and M. C. Rillig. 2006. The invasive plant species Centaurea maculosa alters arbuscular mycorrhizal fungal communities in the field. Plant and Soil 288:81-90.

Newsham, K. K., A. H. Fitter, and A. R. Watkinson. 1995. Multi-functionality and biodiversity in arbuscular mycorrhizas. Trends in Ecology \& Evolution 10:407411.

Nijjer, S., W. E. Rogers, and E. Siemann. 2007. Negative plant-soil feedbacks may limit persistence of an invasive tree due to rapid accumulation of soil pathogens. Proceedings of the Royal Society B-Biological Sciences 274:2621-2627.

Ramakrishnan, A. P., T. Musial, and M. B. Cruzan. 2010. Shifting dispersal modes at an expanding species' range margin. Molecular Ecology 19:1134-1146.

Remy, W., T. N. Taylor, H. Hass, and H. Kerp. 1994. 4-hundred-mission-year-old vesicular arbuscular mycorrhizae. Proceedings of the National Academy of Sciences of the United States of America 91:11841-11843.

Reynolds, H. L., A. Packer, J. D. Bever, and K. Clay. 2003. Grassroots ecology: Plantmicrobe-soil interactions as drivers of plant community structure and dynamics. Ecology 84:2281-2291.

Robinson, D. and A. Fitter. 1999. The magnitude and control of carbon transfer between plants linked by a common mycorrhizal network. Journal of Experimental Botany 50:9-13.

Rosenthal, D. M., A. P. Ramakrishnan, and M. B. Cruzan. 2008. Evidence for multiple sources of invasion and intraspecific hybridization in Brachypodium sylvaticum (Hudson) Beauv. in North America. Molecular Ecology 17:4657-4669.

Roy, B. A., T. Coulson, W. Blaser, T. Policha, J. L. Stewart, G. K. Blaisdell, and S. Guesewell. 2011. Population regulation by enemies of the grass Brachypodium sylvaticum: demography in native and invaded ranges. Ecology 92:665-675.

Scheublin, T. R., R. S. P. Van Logtestijn, and M. G. A. Van der Heijden. 2007. Presence and identity of arbuscular mycorrhizal fungi influence competitive interactions between plant species. Journal of Ecology 95:631-638.

Selosse, M. A., F. Richard, X. H. He, and S. W. Simard. 2006. Mycorrhizal networks: des liaisons dangereuses? Trends in Ecology \& Evolution 21:621-628.

Sikes, B. A. 2010. When do arbuscular mycorrhizal fungi protect plant roots from pathogens? Plant signaling \& behavior 5:763-765. 
Simard, S. W. and D. M. Durall. 2004. Mycorrhizal networks: a review of their extent, function, and importance. Canadian Journal of Botany-Revue Canadienne De Botanique 82:1140-1165.

Smith, F. A., E. J. Grace, and S. E. Smith. 2009. More than a carbon economy: nutrient trade and ecological sustainability in facultative arbuscular mycorrhizal symbioses. New Phytologist 182:347-358.

Smith, S. E., E. Facelli, S. Pope, and F. A. Smith. 2010. Plant performance in stressful environments: interpreting new and established knowledge of the roles of arbuscular mycorrhizas. Plant and Soil 326:3-20.

Smith, S. E. and D. J. Read. 2008. Mycorrhizal Symbiosis. Third edition. Academic Press.

Song, Y. Y., R. S. Zeng, J. F. Xu, J. Li, X. Shen, and W. G. Yihdego. 2010. Interplant Communication of Tomato Plants through Underground Common Mycorrhizal Networks. Plos One 5.

Suding, K. N., W. S. Harpole, T. Fukami, A. Kulmatiski, A. S. MacDougall, C. Stein, and W. H. van der Putten. 2013. Consequences of plant-soil feedbacks in invasion. Journal of Ecology 101:298-308.

Taylor, T. N., W. Remy, H. Hass, and H. Kerp. 1995. Fossil arbuscular mycorrhizae from the early Devonian. Mycologia 87:560-573.

Theoharides, K. A. and J. S. Dukes. 2007. Plant invasion across space and time: factors affecting nonindigenous species success during four stages of invasion. New Phytologist 176:256-273.

Torchin, M. E. and C. E. Mitchell. 2004. Parasites, pathogens, and invasions by plants and animals. Frontiers in Ecology and the Environment 2:183-190.

Troelstra, S. R., R. Wagenaar, W. Smant, and B. A. M. Peters. 2001. Interpretation of bioassays in the study of interactions between soil organisms and plants: involvement of nutrient factors. New Phytologist 150:697-706.

van der Heijden, M. G. A. 2004. Arbuscular mycorrhizal fungi as support systems for seedling establishment in grassland. Ecology Letters 7:293-303.

van der Heijden, M. G. A., A. Wiemken, and I. R. Sanders. 2003. Different arbuscular mycorrhizal fungi alter coexistence and resource distribution between cooccurring plant. New Phytologist 157:569-578.

Von Thun, T. 2013. Nutrient Exchange through Hyphae in Intercropping Systems Affects Yields. Natural Sciences Education 42:24-27.

Wagg, C., J. Jansa, M. Stadler, B. Schmid, and M. G. A. van der Heijden. 2011. Mycorrhizal fungal identity and diversity relaxes plant-plant competition. Ecology 92:1303-1313.

Walder, F., H. Niemann, M. Natarajan, M. F. Lehmann, T. Boller, and A. Wiemken. 2012. Mycorrhizal Networks: Common Goods of Plants Shared under Unequal Terms of Trade. Plant Physiology 159:789-+.

Wehner, J., P. M. Antunes, J. R. Powell, J. Mazukatow, and M. C. Rillig. 2010. Plant pathogen protection by arbuscular mycorrhizas: A role for fungal diversity? Pedobiologia 53:197-201.

Weremijewicz, J. and D. P. Janos. 2013. Common mycorrhizal networks amplify size inequality in Andropogon gerardii monocultures. New Phytologist 198:203-213. 
Wilson, G. W. T., D. C. Hartnett, and C. W. Rice. 2006. Mycorrhizal-mediated phosphorus transfer between tallgrass prairie plants Sorghastrum nutans and Artemisia ludoviciana. Functional Ecology 20:427-435.

Wisz, M. S., J. Pottier, W. D. Kissling, L. Pellissier, J. Lenoir, C. F. Damgaard, C. F. Dormann, M. C. Forchhammer, J.-A. Grytnes, A. Guisan, R. K. Heikkinen, T. T. Hoye, I. Kuehn, M. Luoto, L. Maiorano, M.-C. Nilsson, S. Normand, E. Ockinger, N. M. Schmidt, M. Termansen, A. Timmermann, D. A. Wardle, P. Aastrup, and J.-C. Svenning. 2013. The role of biotic interactions in shaping distributions and realised assemblages of species: implications for species distribution modelling. Biological Reviews 88:15-30.

Zabinski, C. A., L. Quinn, and R. M. Callaway. 2002. Phosphorus uptake, not carbon transfer, explains arbuscular mycorrhizal enhancement of Centaurea maculosa in the presence of native grassland species. Functional Ecology 16:758-765. 